This is the accepted version of the following article:

Carrascosa L.G., Huertas C.S., Lechuga L. M.. Prospects of optical biosensors for emerging label-free RNA analysis. TrAC - Trends in Analytical Chemistry, (2016). 80. : 177 - . 10.1016/j.trac.2016.02.018,

which has been published in final form at https://dx.doi.org/10.1016/j.trac.2016.02.018 @ https://dx.doi.org/10.1016/j.trac.2016.02.018. This manuscript version is made available under the CC-BY-NC-ND 4.0 license http://creativecommons.org/licenses/by-nc-nd/4.0/ 


\title{
Prospects of optical biosensors for emerging label-free RNA analysis
}

\author{
Laura G. Carrascosa ${ }^{1, \xi, *}$, César S. Huertas ${ }^{1}$ and Laura M. Lechuga ${ }^{1}$ \\ ${ }^{1}$ Nanobiosensors and Bioanalytical Applications Group. Catalan Institute of Nanoscience and \\ Nanotechnology (ICN2), CSIC, The Barcelona Institute of Science and Technology and CIBER-BBN, \\ Campus UAB, Ed-ICN2, 08193 Bellaterra, Barcelona, Spain \\ *Corresponding author: Icarrascosa@cin2.es \\ ${ }^{\S}$ Current contact address (not related to this work): Centre for Personalized Nanomedicine. Australian Institute for \\ Bioengineering \& Nanotechnology (AIBN). The University of Queensland. Brisbane (QId) 4072. Australia. \\ Igcarrascosa@uq.edu.au
}

\section{Abstract}

RNA is critical in countless cellular processes, and researchers are constantly discovering new types and attributing them different roles. Consequently, a growing interest in efficient RNA analysis has arisen. However, RNA detection is complicated and generally requires the use of labels. Major efforts are being devoted to conceive new approaches for RNA analysis with no need of markers. Optical biosensing is a highly sensitive approach that circumvents many of conventional methods' limitations. Lately, label-free applications with optical biosensors have been developed for short as well as for long RNAs. The low limits of detection at the pM level enabled by optical biosensors, together with a fast analysis, their reusability and the label-free scheme of operation, clearly highlight them among the most promising next-generation RNA screening platforms. This review covers the most relevant optical biosensor platforms and their potential for enabling sensitive and label-free RNA analysis.

Keywords: RNA, optical biosensor, label-free detection, microdevices 


\section{RNA, a key player in the biology of cells}

Gene expression is finely regulated in cells for the proper management of protein production and their contents in the right place at the correct time, guarantying the perfect equilibrium necessary for ensuring cell survival. Great number of macromolecules and processes are involved, making it more and more difficult to elucidate which mechanism leads the cell to choose one pathway or another. Recently, researchers have focused on the multiple and

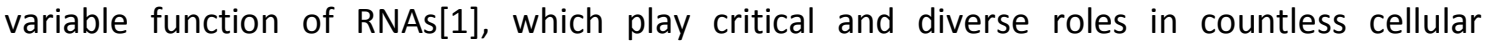
processes. Current methodological advances, including bioinformatics, microarray-based, biochemical and deep-sequencing studies, are revealing new insights into the roles that the regulation of RNA has in generating organism complexity from a relatively small number of genes.

Although they share the same nature, the RNA family is very diverse - in sequence and structure- having different and crucial roles in cell biology (see Table 1)[2-14]. Depending on whether they are involved in protein production or other regulatory functions, they have been classified into protein coding RNAs and non-coding RNAs (nc-RNAs)[15]. Protein coding RNAs are solely represented by the messenger RNA (mRNA), though constituting a large family of RNA molecules that convey the genetic information from the DNA, directly serving as templates for the protein translation. On the contrary, the ncRNA family covers RNAs of many different lengths (from $\sim 20$ to $\sim$ several $\mathrm{kb}$ ) and properties, most of whose functions are unknown. Although many classifications have been proposed the most widely accepted is that based on their structural or house-keeping roles and their regulatory role (Table 1). At the same time, ncRNAs playing regulatory roles are sub-classified according to their length in short ( 20-200 nt) and long nc-RNAs (200 nt up to several Kb).

Until recently, ncRNAs were supposedly inert; but far from being of any usefulness, they have demonstrated to account for most of the cell's genomic output $[9,16]$ and display a very wide 
repertoire of biological functions such as cell cycle regulation, pluripotency, retrotransposon silencing, meiotic entry, telomere length, imprinting or dosage compensation. To execute their function, ncRNAs can either control the transcription or translation of proteins via a number of mechanisms including provision of the machinery for translation (i.e., rRNAs and tRNAs), mediating in the splicing process (e.g., intronic RNAs) remodeling the epigenome (i.e., DNA methylation and histone modification) $[17,18]$ or by interacting with other RNAs and proteins. For example, miRNAs in the cytoplasm can interact with the mRNA product and inhibit its translation process. At the transcriptional level, nc-RNAs such as In-ncRNAs can interact with the genomic DNA via formation of duplexes $[13,19-23]$ or triplexes $[6,9,11]$-an epigenetic pathway that has only recently been discovered $[9,11,24]$, and recruit other protein regulator factors to alter gene expression. Importantly, these functions are not limited to the cell environment where the nc-RNA has been transcribed. Some non-coding RNAs can be exported out-of-cells via exosomes $[25,26]$ or freely circulate into the bloodstream [27]. This enables these ncRNAs to target other cells from distant organs. Exportation of RNA from cells is paramount in the onset of many diseases (e.g., cancer); thus, researchers have endeavored to identify biomarkers in these pathways that can be exploited for early diagnosis and treatment [28].

Nonetheless, the remarkable plasticity of RNA can even surpass the coding/non-coding classification. Recent investigations [4] are showing that protein-coding and non-coding RNAs might not be mutually exclusive; some RNAs can function both as mRNAs and as functional ncRNAs, thereby RNA should be rather regarded as a multi-tasking molecule that can produce multiple products and that comprises a hidden stage of various levels of gene expression players and controllers. 
Due to the increasingly recognized physiological importance of RNA in physiology and development, along with recent ground-breaking insights into its functions, RNA has been catapulted to the research forefront. RNA regulatory networks may determine most of our complex characteristics, which play a significant role in diseases and constitute an unexplored world of genetic variation both within and between species.

\section{Challenging aspects of RNA detection}

Regardless of the method employed for RNA analysis, there are intrinsic features on RNA molecules that deserve careful consideration for successfully designing a detection assay. These features can be summarized under the five " $\mathrm{S}$ 's" criteria, i.e., stability, sensitivity, specificity, size, and structure [29]:

Stability: RNA is relatively unstable at room temperature, and it is extremely sensitive to the destructive action of ribonucleases and alterations in $\mathrm{pH}[30]$. However, there are some exceptions, such as circulating RNAs in the bloodstream, which are stabilized and protected by other molecules and structures (e.g., exosomes).

Sensitivity: Cellular concentrations for many RNA types are typically very low. This, together with the low stability of RNA, leads to the need of very sensitive methods for RNA detection. However, many conventional techniques does not provide that sensitivity [31] requiring microgram quantities of total RNA - equivalent to over million cells-to achieve detection. This might become problematic when the sample comes from precious sources like biopsies or microdissections. The challenge of RNA detection goes forward when it is intended for capturing RNAs present in serum or plasma (i.e. circulating RNAs) which might exhibit extremely low concentration levels. In this regard, the method employed for extraction of 
these RNAs also play a crucial role in the quality and quantity of RNA extracted and can directly impact the sensitivity of the method employed for detection.

Specificity: RNA molecules of the same family (e.g., mRNA) often share physicochemical properties [32] and even share portions of sequence. For example, the different isoforms generated by the alternative splicing of a gene share one or more exonic sequences that might complicate the specific detection of one of them (i.e., detection without cross-talk from the other). The same problem arises with pre-microRNAs (pre-miRNAs) and its final miRNA product, since the miRNA sequence is already contained within the pre-miRNA one. Also closerelated RNA sequences, such as those from members of the same miRNA family might only differ in one or few nucleotides, making their accurate detection challenging.

Size: RNA types vary greatly in length according to their function, they can go from 18 nucleotides (nt) to several thousands. For example, non-coding RNAs such as microRNAs can be as short as 18 to $20 \mathrm{nt}$, whereas other RNAs such as mRNAs, rRNAs and InRNAs are very long (> $200 \mathrm{nt}$ ). Size affects detection in many ways: for instance, short RNAs are difficult to detect, as they have the same length as the primers used in most detection methods, whereas long probes hybridize well but have poor sequence specificity.

Structure: A hallmark of RNAs is that they tend to be very structured, especially as they increase in length. Unlike DNA, RNA has ribose within the nucleic acid backbone, which provides an extra oxygen atom that is free to promote further interactions between nucleotides. Pairing of local nucleotides generates secondary structures (e.g. hairpins and stem loops), while interactions among distantly located sequences generate tertiary structures [33]. The 3D-structure of an RNA molecule is essential to its biological function, but this inherent geometry can impair hybridization of RNA to a capturing probe [34]. 


\section{Methods for RNA analysis}

\subsection{Conventional methods for RNA analysis}

Current methods for RNA analysis are mostly based on processive PCR-based technologies whereby amplified products of reverse-transcribed RNAs are analyzed. This approach affords semi-quantitative data on a limited number of expressed genes. For the simultaneous test of thousands of expressed genes (expression profiling), micro- and nano-arrays are more appropriate tools $[35,36]$. Other conventional methods, such as Northern Blot or Ribonuclease Protection Assay (RPA) are also common, but achieving a high level of multiplexing is more challenging.

Even the best of these RNA detection methods is limited by the $5 \mathrm{~S}$ 's above mentioned, requiring especial strategies to deal with them. For example, to overcome sensitivity, most of them incorporate some kind of sample amplification and/or signal amplification [37]. While sample amplification strategies amplify RNA samples prior to detection, either exponentially or linearly (i.e., using PCR or RNA/DNA polymerase-based methodologies), signal amplification strategies amplify the signal from labeled targets (e.g. using 3DNA dendrimers, quantum dots or branched DNA). Labeling is indeed a major requirement for most RNA detection methods since they are not only critical for sensitivity, but for increasing specificity. They become even more essential when using multiplexed approaches such as microarrays. Conversely, the labeling process makes detection slower, costlier and less reliable, since it is often difficult to precisely control the number of labels on each molecule across different experiments. Moreover, due to some of the " $5 \mathrm{~S}^{\prime} \mathrm{s}$ " RNA intrinsic features, such as RNA size variation and 2D/3D structure; it is complex to equally label all species of a particular RNA type in the sample regardless of specific sequence or structure. For example small RNAs labeling can be particularly complicated to perform in a reliable way, as their short size impedes direct 
incorporation of labels by ligation or chemical modification [38]. When any label signal bias arises, quantitative analysis becomes challenging.

In addition to the " $5 \mathrm{~S}^{\prime} \mathrm{s}$ " issues, there are also many others affecting the reliability of RNA analysis. Template preparation and the dispensing of reagents might be subjected to a certain degree of variability and contamination when different operators prepare multiple templates, which can only be reduced using expensive robotized systems [35]. For example, the reliability of RNA detection via micro/nanoarrays has been questioned, as they are influenced by array production, RNA extraction, probe labeling, hybridization conditions and image analysis [3942].

As a consequence, standardization of RNA detection is non-trivial [30, 31, 37]. There is a real need for the development of novel detection methods tailored to deal with problematic intrinsic features of RNA, namely, easy-to-use, highly-sensitive diagnostic devices that provide quantitative data on RNAs from crude biological extracts, and that do not require reversetranscription, amplification or labeling.

\subsection{Biosensors as ideal platforms for label-free RNA analysis}

The ideal screening platform for RNA would be, above all, label-free, enabling the access to the entire target RNA population in the sample; consequently, the results would be more reproducible and reliable, not depending on the number of labeled molecules.

Current label-free assay biosensor technologies provide a rapid and often real-time analysis, affording direct measurement of the affinity, kinetics and thermodynamics of biomolecular interactions in vitro-information that is difficult, if not impossible, to collect by other 
methods. These technologies can provide the clearest-and most quantitative-biochemical characterization of molecular interactions available today [43].

Albeit obviating the use of labels is crucial for improving current methods for RNA analysis, several other features are desired, such as greater specificity, sensitivity and reproducibility; amenability to the full range of RNA lengths; and the ability to detect structured targets. Labelfree based biosensors are emerging as ideal tools for the next-generation of RNA detection methods since they can offer rapid, label-free detection of biomolecules of any type with excellent specificity, sensitivity and reproducibility [43-48]. In addition, recent advances in nanotechnology have triggered the development of novel nanobiosensors, which are gradually progressing from the lab to the clinic. Future lab-on-a-chip devices incorporating an array of nanobiosensors could be employed to rapidly and simultaneously screen various analytes at low cost and using minimum volumes of physiological sample [49-52].

The success achieved with biosensors derives from their basic composition: a biosensor contain a biological component, the receptor, which recognizes a target molecule in a specific way; and a signal-generating component, the transducer, which detects the resulting biomolecular interaction and converts this interaction into a measurable signal [53] (see Fig. 1). The presence and concentration of biological molecules in a given medium are measured by translating the biochemical interaction occurring at the sensing surface into a quantitative physical signal. This implies that the receptor(s) used must be previously immobilized onto the transducer surface and be highly specific for the target analyte(s). Biofunctionalization of the sensor surface is a critical step for ensuring high specificity and sensitivity [54]. Indeed, although sensitivity is highly dependent on the transducer method, astonishing results can be obtained when biofunctionalization is finely optimized $[55,56]$. 
The working principle of a biosensor depends on the type of transducer used, which is selected according to the analysis required. The most employed are electrochemical transducers and optical transducers [57-59]. Electrochemical biosensors offer excellent sensitivity and are highly amenable to miniaturization and to multiplexing detection; however they usually demand labeling and/or amplification strategies to generate a sensitive reaction, which in turn might complicate the detection scheme [60]. Optical sensors afford label-free detection with high sensitivity; they can be also miniaturized and multiplexed although the instrumentation can be complex [58]. As optical methods are the most feasible for label-free detection this review will focus only on recent advances in RNA detection achieved by optical biosensors.

\subsubsection{Optical biosensor platforms}

Optical biosensors based on the detection of changes in the refractive index (RI) [61] in the vicinity of the sensor surface are the most employed for label-free analysis. In these biosensors the binding of the analyte to its specific bioreceptor produces a local change in the refractive index at the sensing surface that is evaluated by the transducer. Refractive index changes are probed by the evanescent electromagnetic field that is generated in either guided or resonant optical modes traveling in the transducer. An evanescent wave is a near-field standing wave whose intensity exhibits exponential decay with distance from the boundary at which the wave is formed; it can range from a few tens to a few hundreds of nanometers, exhibiting the highest intensity at the sensor surface. As the optical detection of the local changes in refractive index is confined to the sensing surface-where the target is captured by the receptor-these methods are insensitive to the presence of unbound analyte or to other interfering molecules in the bulk solution. Moreover, detection is related to the sample concentration or surface density, instead of to the total sample mass, since the detection signal does not scale down with the sample volume. This characteristic is particularly attractive when a small detection volume is involved, and it is advantageous over other labeled-based 
methods, whose signal usually depends on the total number of analytes in the detection volume.

The main types of RI-based biosensors (extensively reviewed in refs [61-66]) are:

(i) Surface Plasmon Resonance (SPR) biosensors (see Fig. 2A): They are based on the generation of a surface plasmon wave, a charge density oscillation that occurs at the interface of a metal (the transducer surface, typically gold, onto which the bioreceptors are immobilized) and a dielectric [67]. There are several configurations for SPR sensors, the most widespread of which is the Krestschmann configuration. SPR is a well-known technology and is commercialized by several companies worldwide. SPR is a very sensitive biosensor technique, but is challenging for multiplexing. There are other plasmonic configurations with better multiplexing capabilities, such as Localized Surface Plasmon Resonance (LSPR) sensors (which use metal nanostructures) and Surface Plasmon Resonance imaging (SPRi) sensors (based on the spectroscopy analysis of the whole sensor surface where different receptors have been spotted in separated dots; Figure 2B). Other technique, Surface Enhanced Raman Scattering (SERS) (excited by localized surface plasmon resonances) can afford a high level of sensitivity and it is particularly interesting for multiplexing, but it is more complex to handle and integrate. In general, SPR-based biosensors can reach detection limits in the nM-pM range, and this limit can be even improved by using non-labeling target amplification strategies (e.g., use of secondary antibodies, enzymatic reactions or nanoparticles).

(ii) Resonant waveguide based biosensors: In these sensors the incident light is generally coupled in a waveguide at a specific resonant angle, and the guided mode shows a strong evanescent field [62]. Consequently, the resonant angle is sensitive to the RI change near the waveguide surface. Examples include resonant mirrors $[68,69](\mathrm{RM})$ and metal-clad waveguides (MCWG) [70]. 
(iii) Integrated interferometer-based biosensors: They are based on interferometric evaluation of the changes in the wave-vector of a guided mode as a consequence of the biomolecular recognition event. The most relevant examples are the Mach-Zehnder [71] and the Young interferometers [72]. They are extremely sensitive-orders of magnitude higher than SPR- but their integration and multiplexing are technologically complex. Recently, an innovative type of interferometer-based biosensor, the bimodal waveguide (BMW) sensor, has been introduced [52]. It offers the high sensitivity of interferometric biosensors, as well as greater amenability to integration, miniaturization and multiplexing (see Fig. 2C).

(iv) Micro-ring resonators based biosensors (see Fig. 2D): they constitute an emerging sensing technology where ring-shaped waveguide structures (micro-rings) are optically coupled to one or more linear waveguides, patterned on a planar surface. The light propagates inside the micro-ring in the form of whispering gallery modes (WGMs) which generate an evanescent field at the resonator surface. The effective light-analyte interaction length of a ring resonator sensor is determined by the number of revolutions of the propagating light supported by the resonator [73].

(v) Optical fiber-based biosensors: Like planar waveguide biosensors, optical fibers exhibit an evanescent field along their structure that penetrates into the external medium, where the biosensor reaction occurs. Interesting types include nanofibers, Bragg fibers and Fabry-Perot based fibers [74].

(vi) Photonic crystal (PC)-based biosensors (see Fig. 2E): photonic crystals have a periodic dielectric structure with a periodicity on the order of the light wavelength that forms a photonic bandgap. When a photonic "defect" is introduced within the bandgap, the light resonant with the defect mode can propagate in the PC. Since the spectral position of the defect mode is highly sensitive to the change in the local environment around the defect, it can be used as the sensing transduction of the binding of the analyte molecules to the 
defect. Photonic crystal-based biosensors have the advantage of strong light confinement, provided by the photonic cavity, and high flexibility for adjusting the defect mode wavelength across the photonic bandgap [75].

\section{Current applications for detection of RNA using optical biosensors}

To date, most of the optical biosensor applications for RNA analysis have chiefly focused on miRNAs, m-RNAs, r-RNA and recently, on RNAs potentially interacting with the genomic DNA via formation of triplexes. Despite the extensive literature on many different biosensor schemes employed to detect nucleic acids, most are mainly devoted to DNA oligonucleotides [76]. In principle, given the similarities between DNA and RNA, the results obtained for DNA oligonucleotides could be considered valid for the homologous RNA sequence. However, extraction is really a challenging aspect of RNA determination, which can strongly influence the analytical performances of biosensing tools when addressing detection directly from real biological samples. Therefore, since the RNA-detection capability of these schemes has not been demonstrated with real RNA samples, applications using DNA oligos have not been considered in this review.

There are also examples of indirect RNA detection, whereby the RNA sample is first converted into cDNA by methods such as RT-PCR. Given that the conversion step complicates the detection and limits the biosensing technology from offering any unique advantage over reverse-transcribed based conventional methods, these applications have not been considered either. This review has therefore strictly focused on biosensor applications for directly detecting different types of RNA (including synthetic RNA) in biological samples without any reverse-transcribed amplification. A summary of the main outcomes and analytical performances of each method in the detection of the different RNA types is depicted in Table 2. 


\subsection{Detection of small RNAs}

Several types of optical biosensors have been employed to detect small RNAs (mostly in the range of $20 \mathrm{nt}$ ) such as miRNAs. Surface Plasmon Resonance biosensor and its microarray format homolog, SPRi, have shown to be incredibly versatile and effective for direct sensing of miRNA. However, the short length of small RNAs translates to a small mass to be detected, which reduces their capability to achieve high sensitive detection (sensitivity is typically in the $\mathrm{nM}$ range). To enhance sensitivity researchers have employed a variety of nontarget labeling amplification strategies, which enable detection limits at the $\mathrm{pM}$ or even $\mathrm{fM}$ levels. The disadvantage of these strategies is that the addition of one or more post-detection steps requires longer measuring times. Typically, standard SPR detection takes less than few minutes; however, addition of an amplification strategy can extend the read-out under $1 \mathrm{~h}$, which is still reasonable. For example, Sipova et al. [77] achieved rapid, label-free detection of miRNA-122 from mouse liver tissue at $0.2 \mathrm{nM}$, using a novel, high-performance portable SPR sensor. But they managed to lower their previous detection limit by two orders of magnitude-down to a reported value of $2 \mathrm{pM}$-by performing an amplification step in which the captured miRNA is subsequently recognized by an antibody that exhibits affinity to the RNA*DNA hybrids. Nonetheless, the linear range of evaluation only extends to miRNA concentrations up to $10 \mathrm{nM}$ and $0.1 \mathrm{nM}$ for the hybridization and antibody-recognition steps, respectively (Fig. 3A). The sensitivity for evaluating RNA concentrations under these values is limited and, probably, unreliable. Despite the additional antibody step, the total time for miRNA detection was only $35 \mathrm{~min}$. A similar strategy was developed by Nasheri et al. [78]. They directly detected synthetic miR-122 using a SPRi biosensor achieving a detection limit of 40 $\mathrm{nM}$. After hybridization, the signal was amplified using the protein $\mathrm{p} 19$, which has affinity towards the hybrid RNA/RNA duplex. Although this strategy is interesting for demonstrating the utility of $\mathrm{p} 19$ for the recognition of miRNA-bound probes, this approach does not appear to be as effective as the antibody-recognition one: Nasheri et al. were only able to lower their 
detection limit by one order of magnitude, whereas Sipova et al. achieved two orders of magnitude. However, the worse detection limit of the former could also be due to the technique itself, as SPRi is less sensitive than standard SPR.

Detection can also be largely improved through the use of more effective strategies for amplification and biofunctionalization. For example, Fang et al. analyzed three types of synthetic miRNAs (miR-16, miR-23b, and miR-122b) by SPRi achieving an incredible detection limit of only 5 attomoles (10 fM) [56]. They optimized the biofunctionalization by (i) using locked nucleic acid (LNA) probes, which have demonstrated to increase both the sensitivity and the specificity of hybridization [79] and (ii) subsequently recirculating the miRNA target solution over the LNA-derivatized sensing surface for $4 \mathrm{~h}$. Although this is a long assay period, it enabled better saturation of the receptors for a given miRNA concentration, thus obviating the use of higher concentrations. Regardless, the cornerstone of their success was probably the impressive degree of amplification that they obtained using a two-step approach involving enzymatic polyadenylation extension of captured miRNAs followed by recognition of the generated polyadenylated tails by nanoparticles coupled to polythymidine oligonucleotides (see Fig. 3B). The real-time capability of this sensor enabled monitoring the entire procedure in real-time, including the polyadenylation reaction, in which the incorporation of each adenine was observed. The use of total RNA sample extracted from mouse liver tissue as a source for miRNA determination instead of synthetic miRNAs did not affect significantly the analytical performance of this method, which still could demonstrate detection of these miRNAs at femtomolar concentrations. Moreover, they tested the same amplification strategy on a novel optical biosensor technique based on Nanoparticle-Enhanced Diffraction Gratings (NEDG). In this sensor the optical properties of surface plasmons generated on gold gratings are coupled to the optical properties of adsorbed gold nanoparticles [80]. Using this sensor, synthetic miR$122 \mathrm{~b}$ targets were detected at a concentration of $50 \mathrm{pM}$, which was higher than when using 
the SPRi sensor. However, the NEDG sensor could be improved by the ability to tune the plasmon excitation wavelength in the gratings using different types of nanoparticles.

Zhou et al. [81] devised another interesting amplification strategy for SPRi, for the analysis of three synthetic miRNA mimics. They employed DNA-modified silica nanoparticles complementary to the miRNA target for capturing. The target was then fixed to the nanoparticle-DNA sequence by using a T4-ligase enzymatic reaction. Finally, the read-out of the nanoparticle-target pair was done by SPRi using receptor probes arrayed on the sensor surface that were also complementary to the target RNA sequence. The silica-nanoparticle step plays a double role towards enhancing target detection: firstly, it enables purification and concentration of the target, as they can be centrifuged, separated, washed and reconstituted in a smaller microliter volume format; and secondly, it enhances the target recognition signal, as it amplifies the mass loading at the sensor surface. The final result is a biosensor method able to detect multiple ssRNA sequences at concentrations as low as $100 \mathrm{fM}$. Recently, Joshi et al. [82] developed a technology based on solid-state localized surface plasmon resonance (LSPR) consisting of highly sensitive nanostructures (gold nanoprisms). They achieved the direct detection of miRNAs 21 and 10b at a LoD 23-35 fM in plasma extracted total RNA. Detection of the same miRNAs from raw plasma samples without performing the RNA extraction step showed that miRNA concentration in extracted samples was at least 2 -fold lower than in the pure plasma samples. This outcome puts in evidence the large impact of the methodology employed for RNA extraction in the accuracy of detection since it can cause significant loss of miRNAs during the RNA extraction process. The large sensitivity of LSPR, which enables performing detection without the need for sample purification and pre- or postamplification steps place this type of biosensing technology at the forefront of miRNAs detection technologies.

Microring resonators based biosensors demonstrated to be as sensitive as SPR for detecting the changes in refractive index that accompany the binding of a miRNA target. Qavi 
et al. [83] employed arrays of silicon microring resonators to analyze four miRNAs from a clinically-relevant sample of a cell-line model of glioblastoma, with minimal sample preparation (see Fig. 3C). They reached a detection limit of $150 \mathrm{fmol}(\sim 2 \mathrm{nM})$ without any amplification, a similar value to that obtained by SPR; however, they achieved a wider linear dynamic range of more than two orders of magnitude. To achieve this wide range, rather than utilize the absolute wavelength shift, which saturates as miRNAs hybridize to all of the available ssDNA capture probes, they determined the rate at which the resonance peak changes immediately after target introduction, and they used the initial slope response for quantification. The advantages of this approach were the generation of a linear calibration and a decrease in the total assay time $(\sim 10 \mathrm{~min})$.

Driskell et al. [84] employed Surface-Enhanced Raman Spectroscopy (SERS) to detect five different synthetic miRNAs at $\mu \mathrm{M}$ level (but it only requires $1 \mu \mathrm{L}$ of RNA sample) in very short acquisition time (only $10 \mathrm{~s}$ ). Interestingly, they identified single nucleotide polymorphisms that enable discrimination among eight members of the let-7 miRNA family. SERS is a promising method for miRNA detection that enables label-free detection of multiplexed miRNA. However, due to the subtle differences in peak intensity as a function of distinct-but related-sequence composition, the identification of specific sequences requires extensive multivariate analysis. A novel integrated optical biosensor based on a slot waveguide Mach-Zehnder interferometer (MZI) configuration was also developed for multiplex miRNA detection by Liu et al.[85]. It allowed a rapid and accurate detection of two types of miRNAs (miR-21 and let-7a) in human urine samples in a single reaction down to $1 \mathrm{fM}$ level of sensitivity. Moreover, this biosensing platform also demonstrated the ability to identify the single nucleotide polymorphism of the let-7 family of miRNAs. This large sensitivity and specificity alongside its capability for integration put this biosensor a step forward for the development of a point-of-care (POC) test for disease-associated miRNAs. 
While all these methods perform well in terms of specificity and sensitivity in compare to conventional methods, perhaps the main challenge yet to be addressed by optical sensors is to demonstrate simultaneous detection of hundreds or thousands of miRNAs, which is a requirement for some biological applications. Many optical platforms have the potential for massive parallel screening (e.g., SPRi), however, most demonstrations currently available are limited to just few RNA candidates. Therefore, further work is required to fully demonstrate the applicability of optical sensors for miRNA analysis.

\subsection{Detection of long RNAs}

4.2.1. Messenger RNA (mRNA). Messenger RNA (mRNA) analyses are required for understanding certain biological mechanisms, for example, to determine whether changes in mRNA levels correlate to the translation of a given protein and to pinpoint the cell types that exhibit said changes, which in turn might be related to the onset of many diseases. Albeit the number of copies of mRNA in a cell type varies drastically depending on the mRNA type, the number of copies of any given mRNA in a cell extract is usually very low. Thus, mRNA detection requires high sensitivity. Although challenging, the advantage of mRNA biosensing relative to short ones, such as miRNAs, is that they have larger mass and generate larger refractive index changes. As a result, detection of cellular levels of mRNAs does not always require postcapture amplification strategies. Conversely, detection of mRNA suffers from certain drawbacks: for instance, since they are longer they exhibit extensive secondary structures that, together with their large size, might increase the probability of inadequate orientation and poor accessibility. Also, diffusion of mRNA is considerably slower than that of smaller RNA molecules, which translates into longer assay times for comparable sensor responses $[86,87]$. Another problem is specificity: discrimination among the huge variety of mRNAs within a given cell is not trivial; especially among gene-related isoforms (these are generated by transcription of the same gene during alternative splicing and can share one or more exons). 
Taken together, the aforementioned difficulties might explain why the literature contains only a few examples of mRNA detection by optical biosensors. One such example is the work reported by Kindt et al. [87] on the detection of three full length mRNA transcripts (cmyc, $\beta$-actin, and IL-8, in HL-60 cells) using microring resonators. The authors circumvented the problem of accessibility to target regions caused by mRNA structuring by employing chaperone DNA probes (small DNA helper strands complementary to the adjacent matching region) creating a localized duplex region with reduced secondary structures. To ensure specificity during detection, authors selected various capturing sequences for simultaneous use as receptors designed by BLAST searches (to target unique identifier regions of the primary sequence and successfully eliminate cross-hybridization among other mRNA species) and by Mfold prediction (to reduce the likelihood of secondary structures at the matching region). They also employed a two-step, bead-based, signal enhancement strategy to increase the sensitivity and to widen the linear range up to four orders of magnitude, reaching a detection limit of 512 amol ( $2.5 \mathrm{pM})$. Finally, to fully demonstrate the capabilities of the biosensor array for mRNA analysis, Kindt et al. monitored the change in mRNA expression of the three transcripts upon differentiation of HL-60 cells. They detected changes in both myc and al-actin mRNAs, but were unable to detect IL-8 mRNA transcripts due to their lower abundance. This result highlights the need for novel approaches offering greater sensitivity.

A second example of mRNA detection by optical biosensors is a direct-detection strategy recently developed by Huertas et. al [88] using a portable SPR biosensor. The authors explored the analysis and quantification of the two main mRNA isoforms generated by alternative splicing of the pro-apoptotic gene Fas with no need of cDNA conversion and amplification steps, obtaining comparable levels of sensitivity than conventional qRT-PCRbased methodology. In this study, to overcome accessibility problems due to the long length of the mRNA isoforms they performed a simple fragmentation step based on RNA alkaline hydrolysis prior detection. Cross-hybridization was reduced to background levels by 
independently targeting the exon junction of each isoform and employing a highly stringent buffer based on formamide solution, strictly discriminating against the non-complementary isoforms (Fig. 4B). They achieved a limit of detection in the range of hundreds of picomolar (Fig. 4C) and demonstrated the validity of the methodology by using RNA samples from purified HeLa cell-extracts with different ratios and levels of expression of the two isoforms (Fig. 4D).

Optical biosensors have also been employed for the detection of viruses, by the direct determination of their typically long single-stranded RNA (ssRNA). Griffin et al. [89] demonstrated for the first time that the non-linear optical (NLO) properties of gold nanoparticles (hyper-Rayleigh scattering) could be used for screening and quantifying HCV RNA without any modification, offering an excellent detection limit ( $80 \mathrm{pM})$ and selectivity (at the single base-pair mismatch level).

4.2.2. Triplex-forming RNAs and highly structured RNAs. Triplex-forming RNAs (TF-RNAs) and highly structured RNAs are typically long; and can be included in the category of long RNAs. Triplex-forming RNAs sequences contain a poly-purine or poly-pyrimidine motifs that can form a triple helix with a DNA duplex via Hoogsteen base-pairing rules [90]. These motifs are common in many coding and non-coding RNAs sequences [91] and, therefore, are interesting for RNA analysis. They enable RNA sequences to interact with genomic DNA or with proteins that bind triple-helices $[90,91]$.

Long, highly structured RNAs were explored by Carrascosa et al. [92] using a standard SPR sensor. They reported the label-free detection of a highly structured purified 96-mer RNA by exploiting that many In-RNAs contain a triplex motif within their sequence (in this case a 12 nt triplex motif) and could be therefore captured by duplex-receptor, with the subsequent formation of a triplex helix (see Fig. 5B). Their triplex-based strategy, which can be extended to detect TF-RNAs of any type, entailed the use of aminoadenine-modified tail-clamps, as 
capturing duplex-probes. The main advantage incorporated by this new type of tail-clamps is that the duplex receptor largely enhances the stability of a given triplex, maximizing the chances for RNA target capture. With this method, they reported a detection limit of $200 \mathrm{pM}$ (50 fmol) twice lower than with a conventional duplex approach. The most outstanding feature of this method is that it works better for long (e.g. mRNAs or Inc-RNAs) and structured RNA sequences than for short and less structured ones.

The advantages of SPR sensors to monitor biomolecular interactions in real-time and label-free have also proven useful in the discovery of the mode of binding of potential TF-IncRNAs, such as promoter-associated Inc-RNAs. These RNAs have demonstrated to bind DNA by triplex interaction and coordinate regulation of adjacent genes via epigenetics [9, 11]. Recently, SPR has been strategic for uncovering the binding mechanism of Particle, a Inc-RNA involved in regulation of the methionine adenosyltransferase (MAT2A) gene in response to low-dose radiation [9]. Experiments carried-out using conventional SPR demonstrated that Particle creates a triplex structure to regulate the expression of MAT2A via epigenetics.

Structured RNAs have also been analyzed by Boucard et al. [93] using a SPR sensor. They employed a novel binding ligand, a bifunctional-binding aptamer, to simultaneously bind to the two stem-loop structures of the RNA target and reported affinity analyses of these interactions. Nair et al. [94] explored structured RNAs in a completely different way. They were interested on developing a model system for understanding RNA loop-loop interactions using SPR sensors. To address it they used the HIV TAR-TAR* ("kissing hairpin") RNA complex and determined its formation kinetics. By immobilizing one of the hairpin loops (TAR*16) onto a streptavidin chip (by first biotinylating it at the $5^{\prime}$-end), they accurately determined the relative stabilities of two very tight RNA complexes (TAR-TAR* and TARs2U-TAR*) and they also investigated how divalent metal ions affect the RNA complexes.

Finally, Mandir et al. analyzed the RNA-accessible sites of three pre-miRNAs (miRNA precursors of $\sim 75 \mathrm{nt}$ in length) by SPR (Fig. 6). They used an oligonucleotide array fabricated 
with a thin layer of amorphous carbon deposited onto a SPR-active gold substrate [95]. With this approach, the group developed a single "universal array" that contains all possible 6-mer sequences that can bind to any accessible site of RNA molecules of any sequence in a rapid and label-free way. Identification of accessible sites for hybridization within the RNA sequence is an interesting approach for identifying antisense-mediated gene suppression sites. The rich secondary and tertiary structure adopted by RNA molecules leaves only a small portion of its sequence available for hybridization; therefore, those sites are considered to be strongly implicated in binding and regulation during RNA interference (RNAi).

4.2.3. Ribosomal RNA. Ribosomal ribonucleic acid (rRNA) is the RNA component of the ribosome, the cell's essential protein factory. Ribosomal RNAs comprise two subunits: a large subunit (LSU) and a small subunit (SSU). The molecular weight and genetic composition of the subunits differ among organisms, a feature that can be exploited to identify microorganisms. Since rRNA is present in a large amount within the cell, rapid ribosomal RNA analysis of the type of bacterial pathogens in clinical specimens is easy [96].

Two interesting manuscripts report on rRNA analysis using optical biosensors. In the first one, Joung et al. [97] used an SPR sensor and a peptide nucleic acid (PNA) as a capture probe for the detection of $E$. coli 16s rRNA. They employed a signal-enhancing method in which the 16s rRNA, once hybridized onto the PNA receptor layer, interacts with a cationic gold nanoparticle achieving a detection limit of $\sim 58 \mathrm{pg} / \mathrm{mL}(10 \mathrm{fM})$.

Nelson et al. [98] used an SPR imaging array containing DNA probes (15 to 21 bases) designed to be complementary to $16 \mathrm{~S}$ rRNA gene sequences of $E$. coli and $B$. subtilis as well as to a highly conserved sequence found in the rRNA of most bacteria. Using a standard commercial kit for RNA extraction, they were able to detect the RNA in less than 2 hours (including 1 hour for RNA hybridization). They achieved a detection limit of $2 \mu \mathrm{g} / \mathrm{mL}(3.8 \mathrm{nM}$ ) for fragmented $E$. coli in total cellular RNA. 


\section{Conclusions}

Optical biosensors have been garnering increasing attention due to their potential for rapid, direct and label-free analysis of RNA. Although not many examples of RNA detection have been reported to date, the methodology is applicable to a wide range of RNA types. Very interesting approaches have been developed for long RNAs in the monitoring of relevant biological situations, such as alternative splicing or in deciphering their biological mechanism of interaction with target DNA sequences. Promising approaches for the detection of structured RNA targets and small RNAs have also been devised. However, in most of the proposed strategies, detection of small RNAs at an adequate level of sensitivity required nontarget labeling amplification approaches. The principal objectives now facing researchers are the development of more accurate, sensitive and specific biofunctionalization methods, and the creation of more integrated and multiplexed platforms to allow simultaneous monitoring of numerous RNA targets with minimum sample pre-treatment, which should make the devices accessible to non-skilled users.

\section{Acknowledgments}

Authors thank founding from Fundación Botín and EPISENS project of the Spanish Ministry of Science and Innovation (TEC2012-3428). The nanoB2A is a consolidated research group (Grup de Recerca) of the Generalitat de Catalunya and has support from the Departament d'Universitats, Recerca i Societat de la Informació de la Generalitat de Catalunya (2014 SGR 624). ICN2 acknowledges support of the Spanish MINECO through the Severo Ochoa Centers of Excellence Program under Grant SEV-2013-0295. 
[1] R. F. Gesteland, T. R. Cech, and J. F. Atkins, The RNA World, 3rd edn. Cold Spring Harbor Laboratory Press, (2006)

[2] C. Aitken, and J. Lorsch, A mechanistic overview of translation initiation in eukaryotes, Nat Struct Mol Biol, 19, (2012), pp. 568-76

[3] O. Bagasra, A unified concept of HIV latency, Expert Opin. Biol. Ther. , 6, (2006), pp. 1135-1149

[4] M. E. Dinger, K. C. Pang, T. R. Mercer et al., Differentiating Protein-Coding and Noncoding RNA: Challenges and Ambiguities, PLoS Computational Biology, 4, (2008), pp. e1000176

[5] E. J. Finnegan, and M. A. Matzke, The small RNA world, J Cell Sci 116, (2003), pp. 46894693

[6] M. Kanak, M. Alseiari, P. Balasubramanian et al., Triplex-forming MicroRNAs form stable complexes with HIV-1 provirus and inhibit its replication, Appl Immunohistochem Mol Morphol., 18, (2010), pp. 532-545

[7] I. Martianov, A. Ramadass, A. Barros et al., Repression of the human dihydrofolate reductase gene by a non-coding interfering transcript, Nature Biotechnol., 445, (2007), pp. 666-670

[8] V. A. Moran, R. J. Perera, and A. M. Khalil, Emerging functional and mechanistic paradigms of mammalian long non-coding RNAs, Nucl. Acids Res., 40, (2012), pp. 6391-6400

[9] V. B. O'Leary, S. V. Ovsepian, L. G. Carrascosa et al., PARTICLE, a Triplex-Forming Long ncRNA, Regulates Locus-Specific Methylation in Response to Low-Dose Irradiation, Cell Rep, 11, (2015), pp. 474-485

[10] I. Olovnikov, A. Aravin, and K. Fejes Toth, Small RNA in the nucleus: the RNAchromatin ping-pong, Curr Opin Genet Dev, 22, (2012), pp. 164-71

[11] K.-M. Schmitz, C. Mayer, A. Postepska et al., Interaction of noncoding RNA with the rDNA promoter mediates recruitment of DNMT3b and silencing of rRNA genes, Genes \& Development, 24, (2010), pp. 2264-2269

[12] R. J. Taft, C. D. Kaplan, C. Simons et al., Evolution, biogenesis and function of promoter-associated RNAs, Cell Cycle, 8, (2009), pp. 2332-2338

[13] G. Zardo, A. Ciolfi, L. Vian et al., Polycombs and microRNA-223 regulate human granulopoiesis by transcriptional control of target gene expression, Blood, 119, (2012), pp. 4034-46

[14] S. T. Younger, and David R. Corey, Transcriptional gene silencing in mammalian cells by miRNA mimics that target gene promoters, Nucl. Acids Res., 39, (2011), pp. 56825691

[15] J. S. Mattick, and I. V. Makunin, Non-coding RNA, Hum Mol Genet., 15, (2006), pp. R17-29

[16] J. Mattick, Challenging the dogma: the hidden layer of non-protein-coding RNAs in complex organisms, Bioessays, 25, (2003), pp. 930-939

[17] J. Mattick, RNA as the substrate for epigenome-environment interactions: RNA guidance of epigenetic processes and the expansion of RNA editing in animals underpins development, phenotypic plasticity, learning, and cognition., Bioessays, 32, (2010), pp. 548-52

[18] A. Saxena, and i. P. Carninc, Long non-coding RNA modifies chromatin: epigenetic silencing by long non-coding RNAs, Bioessays 33, (2011), pp. 830-9

[19] M. Benhamed, U. Herbig, T. Ye et al., Senescence is an endogenous trigger for microRNA-directed transcriptional gene silencing in human cells, Nat Cell Biol., 14, (2012), pp. 266-75 
[20] D. Kim, P. Saetrom, O. J. Snøve et al., MicroRNA-directed transcriptional gene silencing in mammalian cells, Proc Natl Acad Sci USA, 105, (2008), pp. 16230-5

[21] Y. Tan, B. Zhang, T. Wu et al., Transcriptional inhibiton of Hoxd4 expression by miRNA-10a in human breast cancer cells, BMC Mol Biol, 10, (2009)

[22] R. Place, L. Li, D. Pookot et al., MicroRNA-373 induces expression of genes with complementary promoter sequences, Proc Natl Acad Sci USA, 105, (2008), pp. 160813

[23] J. Toscano-Garibay, and G. Aquino-Jarquin, Regulation Exerted by miRNAs in the Promoter and UTR Sequences: MDR1/P-gp Expression as a Particular Case, DNA and Cell Biology, 31, (2012), pp. 1358-64

[24] I. Grummt, and G. Längst, Epigenetic control of RNA polymerase I transcription in mammalian cells., Biochim Biophys Acta., 1829, (2013), pp. 393-404

[25] H. Valadi, K. Ekström, A. Bossios et al., Exosome-mediated transfer of mRNAs and microRNAs is a novel mechanism of genetic exchange between cells, Nat Cell Biol. , 9, (2007), pp. 654-9

[26] J. C. Brase, D. Wuttig, R. Kuner et al., Serum microRNAs as non-invasive biomarkers for cancer, Mol Cancer, 9, (2010), pp. 306

[27] A. Turchinovich, L. Weiz, A. Langheinz et al., Characterization of extracellular circulating microRNA, Nucl. Acids Res. , 39, (2011), pp. 7223-7233

[28] X. Chen, H. Liang, J. Zhang et al., Horizontal transfer of microRNAs: molecular mechanisms and clinical applications, Protein Cell, 3, (2012), pp. 28-37

[29] S. Acharya, Some aspects of physicochemical properties of DNA and RNA, Acta Universitatis Upsaliensis. Digital Comprehensive Summaries of Uppsala Dissertations from the Faculty of Science and Technology, 164, (2006), pp. 74 pp

[30] S. Fleige, and M. Pfaffl, RNA integrity and the effect on the real-time qRT-PCR performance, Mol Aspects Med, 27, (2006), pp. 126-39

[31] S. Imbeaud, E. Graudens, V. Boulanger et al., Towards standardization of RNA quality assessment using user-independent classifiers of microcapillary electrophoresis traces, Nucleic Acids Res, 33, (2005), pp. e56

[32] Z. Dvořák, J.-M. Pascussi, and M. Modrianský, Approaches to messenger RNA detection - comparison of methods, Biomed. Papers 147, (2003), pp. 131-135

[33] Y. Wan, M. Kertesz, R. C. Spitale et al., Understanding the transcriptome through RNA structure, Nature reviews. Genetics, 12, (2011), pp. 641-655

[34] N. Toschi, Influence of mRNA Self-Structure on Hybridization: Computational Tools for Antisense Sequence Selection, Methods, 22, (2000), pp. 261-269

[35] S. A. Bustin, Quantification of mRNA using real-time reverse transcription PCR (RTPCR): Trends and problems, Journal of molecular endocrinology, 29, (2002), pp. $23-39$

[36] D. Howbrook, A. van der Valk, M. O'Shaughnessy et al., Developments in microarray technologies, Drug Discov Today, 8, (2003), pp. 642-51

[37] J. Mora, and R. Getts, High-sensitivity detection methods for low-abundance RNA species: applications for functional genomics research, Expert Rev Mol Diagn, 7, (2007 ), pp. $775-85$

[38] L. Goff, M. Yang, J. Bowers et al., Rational probe optimization and enhanced detection strategy for microRNAs using microarrays., RNA Biol., 2, (2005), pp. 93-100

[39] E. Marshall, Getting the noise out of gene arrays, Science, 306, ( 2004), pp. 630-631

[40] H. Fathallah-Shaykh, Microarrays: applications and pitfalls, Arch Neurol, 62, (2005), pp. 1669-72

[41] P. Park, Y. Cao, S. Lee et al., Current issues for DNA microarrays: platform comparison, double linear amplification, and universal RNA reference, J Biotechnol, $112,(2004)$, pp. $225-45$

[42] G. Smyth, Y. Yang, and T. Speed, Statistical issues in cDNA microarray data analysis, Methods Mol Biol 224, (2003), pp. 111-36 
[43] R. Halai, and M. Cooper, Using label-free screening technology to improve efficiency in drug discovery, Expert Opin Drug Discov, 7, (2012), pp. 123-31

[44] P. D'Orazio, Biosensors in clinical chemistry - 2011 update., Clin Chim Acta, 412, (2011), pp. 1749-61

[45] P. D'Orazio, Biosensors in clinical chemistry, Clin Chim Acta, 334, (2003), pp. 41-69

[46] C. Lunn, Label-free screening assays: a strategy for finding better drug candidates, Future Med Chem, 2, (2010), pp. 1703-16

[47] H. Hunt, and A. Armani, Label-free biological and chemical sensors, Nanoscale., 2, (2010), pp. 1544-59

[48] J. Perkel, Who needs labels? Macromolecular interaction sans labels, Science, 19, (2009), pp. 1561-1565

[49] L. Bellan, D. Wu, and R. Langer, Current trends in nanobiosensor technology, Wiley Interdiscip Rev Nanomed Nanobiotechnol. , 3, (2011), pp. 229-46

[50] H. Song, and T. Park, Integration of biomolecules and nanomaterials: towards highly selective and sensitive biosensors, Biotechnol J, 6, (2011), pp. 1310-6

[51] S. Vaddiraju, I. Tomazos, D. Burgess et al., Emerging synergy between nanotechnology and implantable biosensors: a review, Biosens Bioelectron. , 25, (2010), pp. 1553-65

[52] D. Duval, A. B. González-Guerrero, S. Dante et al., Nanophotonic lab-on-a-chip platforms including novel bimodal interferometers, microfluidics and grating couplers, Lab Chip, 12, (2012), pp. 1987-1994

[53] D. Thevenot, K. Toth, R. Durst et al., Electrochemical biosensors: recommended definitions and classifications, Biosens Bioelectron, 16, (2001), pp. 121- 31

[54] D. Samanta, and A. Sarkar, Immobilization of bio-macromolecules on self-assembled monolayers: methods and sensor applications, Chem Soc Rev., 40, (2011), pp. 256792

[55] L. G. Carrascosa, A. Calle, and L. M. Lechuga, Label-free detection of DNA mutations by SPR: application to the early detection of inherited breast cancer, Anal Bioanal Chem, 393, (2009), pp. 1173-1182

[56] S. Fang, H. Lee, A. Wark et al., Attomole microarray detection of micro-RNAs by nanoparticle-amplified SPR imaging measurements of surface polyadenylation reactions, J Am Chem Soc, 128 (2006), pp. 14044-14046

[57] N. Ronkainen, H. Halsall, and W. Heineman, Electrochemical biosensors, Chem Soc Rev., 39, (2010), pp. 1747-63

[58] A. Washburn, and R. Bailey, Photonics-on-a-chip: recent advances in integrated waveguides as enabling detection elements for real-world, lab-on-a-chip biosensing applications, Analyst., 136, (2011), pp. 227-36

[59] G. Gauglitz, Direct optical detection in bioanalysis: an update, Anal Bioanal Chem., 398, (2010), pp. 2363-72

[60] X. Xu, S. Zhang, H. Chen et al., Integration of electrochemistry in micro-total analysis systems for biochemical assays: recent developments, Talanta, 80, (2009), pp. 8-18

[61] X. Fan, I. M. White, S. I. Shopova et al., Sensitive optical biosensors for unlabeled targets: A review, Analytica Chimica Acta, 6, (2008), pp. 8-26

[62] H. N. Daghestani, and B. W. Day, Theory and Applications of Surface Plasmon Resonance, Resonant Mirror, Resonant Waveguide Grating, and Dual Polarization Interferometry Biosensors, Sensors, 10, (2010), pp. 9630-9646

[63] M.-C. Estevez, M. Alvarez, and L. M. Lechuga, Integrated Optical Devices for Lab-on-achip Biosensing Applications, Laser and Photonics Reviews, 6, (2012), pp. 463-487

[64] D. Wawro, S. Tibuleac, and R. Magnusson, Optical Waveguide-mode Resonant Biosensors. In OPTICAL IMAGING SENSORS AND SYSTEMS FOR HOMELAND SECURITY APPLICATIONS, Advanced Sciences and Technologies for Security Applications, 2, (2006), pp. 367-384 
[65] A. Brecht, and G. Gauglitz, Recent developments in optical transducers for chemical or biochemical applications, Sensors and Actuators B, 38-39, (1997), pp. 1-7

[66] V. M. N. Passaro, F. Dell'Olio , B. Casamassima et al., Guided-Wave Optical Biosensors, Sensors, 7, (2007), pp. 508-536

[67] J. Homola, Surface plasmon resonance-based sensors, Anal Bioanal Chem., 390, (2008), pp. 1221-1222

[68] R. Cush, J. M. Cronin, W. J. Stewart et al., The resonant mirror: a novel optical biosensor for direct sensing of biomolecular interactions Part I: Principle of operation and associated instrumentation, Biosensors and Bioelectronics, 8, (1993), pp. 347-354

[69] P. E. Buckle, R. J. Davies, T. Kinning et al., The resonant mirror: a novel optical sensor for direct sensing of biomolecular interactions part II: applications, Biosensors and Bioelectronics, 8, (1993), pp. 355-363

[70] N. Skivesen, R. Horvath, S. Thinggaard et al., Deep-probe metal-clad waveguide biosensors, Biosensors and Bioelectronics, 22, (2007), pp. 1282-1288

[71] B. Sepúlveda, J. Sánchez del Río, M. Moreno et al., Optical biosensor microsystems based on the integration of highly sensitive Mach-Zehnder interferometer devices, Journal of Optics A: Pure and Applied Optics 8, (2006), pp. S561

[72] G. H. Cross, A. A. Reeves, S. Brand et al., A new quantitative optical biosensor for protein characterisation, Biosensors and Bioelectronics, 19, (2003), pp. 383-390

[73] F. Vollmer, and S. Arnold, Whispering-gallery-mode biosensing: label-free detection down to single molecules, Nature Methods, 5, (2008), pp. 591 - 596

[74] D. J. Monk, and D. R. Walt, Optical fiber-based biosensors, Anal Bioanal Chem., 379, (2004), pp. 931-945

[75] M. R. Lee, and P. M. Fauchet, Two-dimensional silicon photonic crystal based biosensing platform for protein detection, Optics Express,, 15, (2007), pp. 4530

[76] S. Cosnier, and P. Mailley, Recent advances in DNA sensors, Analyst, 133, (2008), pp. 984-91

[77] H. Sipova, S. Zhang, A. M. Dudley et al., Surface Plasmon Resonance Biosensor for Rapid Label-Free Detection of Microribonucleic Acid at Subfemtomole Level Analytical Chemistry Article ASAP, (2010)

[78] N. Nasheri, J. Cheng, R. Singaravelu et al., An enzyme-linked assay for the rapid quantification of microRNAs based on the viral suppressor of RNA silencing protein p19, Anal Biochem., 412, (2011), pp. 165-72

[79] H. Kaur, B. R. Babu, and S. Maiti, Perspectives on chemistry and therapeutic applications of locked nucleic acid (LNA), Chemical Reviews, 107, (2007), pp. 4672 4697

[80] H. Lee, A. Wark, and R. Corn, Enhanced bioaffinity sensing using surface plasmons, surface enzyme reactions, nanoparticles and diffraction gratings, Analyst., 133, (2008), pp. 596-601

[81] W. Zhou, Y. Chen, and R. Corn, Ultrasensitive microarray detection of short RNA sequences with enzymatically modified nanoparticles and surface plasmon resonance imaging measurements, Anal Chem, 83, (2011), pp. 3897-902

[82] G. K. Joshi, S. Deitz-McElyea, M. Johnson et al., Highly specific plasmonic biosensors for ultrasensitive microRNA detection in plasma from pancreatic cancer patients, Nano letters, 14, (2014), pp. 6955-6963

[83] A. Qavi, and R. Bailey, Multiplexed detection and label-free quantitation of microRNAs using arrays of silicon photonic microring resonators, Angew Chem Int Ed Engl., 49, (2010), pp. 4608-4611

[84] J. Driskell, A. Seto, L. Jones et al., Rapid microRNA (miRNA) detection and classification via surface-enhanced Raman spectroscopy (SERS), Biosens Bioelectron, 24, (2008), pp. 917-922 
[85] Q. Liu, Y. Shin, J. S. Kee et al., Mach-Zehnder interferometer (MZI) point-of-care system for rapid multiplexed detection of microRNAs in human urine specimens, Biosensors and Bioelectronics, 71, (2015), pp. 365-372

[86] T. M. Squires, R. J. Messinger, and S. R. Manalis, Making it stick: convection, reaction and diffusion in surface-based biosensors, Nature Biotechnology, 26, (2008), pp. 417426

[87] J. T. Kindt, and R. C. Bailey, Chaperone Probes and Bead-Based Enhancement To Improve the Direct Detection of mRNA Using Silicon Photonic Sensor Arrays, Anal. Chem., 84, (2012), pp. 8067-8074

[88] C. S. Huertas, L. G. Carrascosa, S. Bonnal et al., Monitoring of alternative splicing events in real-time Biosens Bioelectron, In press, available on line, (2015)

[89] J. Griffin, A. K. Singh, D. Senapati et al., Sequence-Specific HCV RNA Quantification Using the Size-Dependent Nonlinear Optical Properties of Gold Nanoparticles, Small, 5, (2009), pp. 839-845

[90] F. A. Buske, J. S. Mattick, and T. L. Bailey, Potential in vivo roles of nucleic acid triplehelices, RNA Biol., 8, (2011), pp. 427-439

[91] R. Zheng, Z. Shen, V. Tripathi et al., Polypurine-repeat-containing RNAs: a novel class of long non-coding RNA in mammalian cells, J Cell Sci. , 123, (2010), pp. 3734-3744

[92] L. G. Carrascosa, S. Gómez-Montes, A. Aviñó et al., Sensitive and label-free biosensing of RNA with predicted secondary structures by a triplex affinity capture method, Nucleic Acids Res, 40, (2012), pp. e56

[93] D. Boucard, J. Toulmé, and C. Di Primo, Bimodal loop-loop interactions increase the affinity of RNA aptamers for HIV-1 RNA structures, Biochemistry, 45, (2006), pp. 1518-24

[94] T. M. Nair, D. G. Myszka, and D. R. Davis, Surface plasmon resonance kinetic studies of the HIV TAR RNA kissing hairpin complex and its stabilization by 2-thiouridine modification, Nucleic Acids Res. , 28, (2000), pp. 1935-1940

[95] J. B. Mandir, M. R. Lockett, M. F. Phillips et al., Rapid Determination of RNA Accessible Sites by Surface Plasmon Resonance Detection of Hybridization to DNA arrays, Anal Chem. , 81, (2009), pp. 8949-8956

[96] J. E. Clarridge III, Impact of 16S rRNA gene sequence analysis for identification of bacteria on clinical microbiology and infectious diseases, Clin Microbiol Rev, 17, (2004), pp. 840-862

[97] H. Joung, N. Lee, S. Lee et al., High sensitivity detection of 16s rRNA using peptide nucleic acid probes and a surface plasmon resonance biosensor, Anal Chim Acta., 630, (2008), pp. 168-73

[98] B. Nelson, M. Liles, K. Frederick et al., Label-free detection of $16 \mathrm{~S}$ ribosomal RNA hybridization on reusable DNA arrays using surface plasmon resonance imaging, Environ Microbiol., 4, (2002), pp. 735-43

[99] D. Armani, T. Kippenberg, S. Spillane et al., Ultra-high-Q toroid microcavity on a chip, Nature, 421, (2003), pp. 925-928 


\section{Figure Captions}

Box 1. Schematic of RNA types and functions

Figure 1. Scheme of the working principle of a biosensor device

Figure 2. Different types of optical biosensors. A) Scheme of a standard SPR biosensor and B) of an SPR imaging biosensor. C) Scheme of an integrated interferometer biosensor based on bimodal waveguides (BiMW): (a) Working principle showing the distribution of the electromagnetic field in the single mode and the bimodal sections; (b) envisioned lab-on-a-chip platform based on BiMW sensors; and (c) photograph of a chip (30 mm×10 mm) containing 16 BiMW interferometers. Reprinted with permission from The Royal Society of Chemistry (ref [52]) D) Photograph of a ring resonator biosensor. Reprinted with permission from ref [99] E) Photograph of a photonic crystal-based biosensor. Reprinted with permission from ref [75].

Figure 3. Detection of small RNAs with optical biosensors. A) Scheme of the two-step assay developed by Sipova et al. for the detection of miRNA-122 with SPR. Examples of the temporal sensor response to the miRNA-122 and its selective antibody, and the corresponding calibration curves, are included below. Reprinted with permission from ref [77] B) Schematic representation of the three-step assay developed by Fang et al. for the detection of miRNA 16, miRNA-122b and miRNA-23b with an SPR imaging platform. The monitoring of polyadenylation after capture of the miRNAs targets along with the calibration curves is also shown. Reprinted with permission from ref [56] C) Multiplexed detection of several miRNAs with the ring resonator based biosensor by Qavi et al. An example of the absolute wavelength shift after miRNA recognition and real-time evaluation of the selected miRNAs are shown. Reprinted with permission from ref [83](Copyright Wiley-VCH Verlag GmbH \& Co. KGaA)

Figure 4. SPR methodology for quantitative evaluation of Fas gene alternatively spliced mRNA isoforms.

(A) Schematic representation of the different RNA and protein isoforms generated by alternative splicing of Fas gene/CD95. (B) Scheme for the label-free and direct detection of alternative spliced variants with an SPR biosensor. (C) SPR calibration plots for Fas57 (up) (R2=0.99) and Fas56 (down) (R2=0.99) DNAprobes using the optimized hybridization and detection conditions. (D) SPR analysis of different HeLa 
cells lineages presenting different expression levels of Fas isoforms for Fas56 DNA-probe. Reprinted with permission from ref [88].

Figure 5. Detection of TF-RNAs developed by Carrascosa et al. using an SPR biosensor. A) Triplexdetection strategy using amino-modified tail-clamp receptors; and B) folding structure of the RNA target. C) Calibration curve of the detection of a purified RNA, and the two-folded enhanced signal obtained with the triplex strategy as compared to the duplex one. Reprinted with permission from Ref [92].

Figure 6. Universal SPR imaging array developed by Mandir et al. comprising all possible 6-mer combinations for high throughput screening of RNA accessible sites. (A) SPRi difference image showing spots of hybridization for a solution $1 \mu \mathrm{M}$ pre-let-7a3. (B) Histogram of the hybridization data obtained from the difference image. The $y$-axis corresponds to the average change in $\%$ reflectivity $(\Delta \% R)$, and the $\mathrm{x}$-axis corresponds to the location of the surface probe along the RNA sequence (Location 1 corresponds to nucleotides 1 through 6). The dotted horizontal line represents the cutoff line. Features with intensity changes greater than the cutoff line are considered accessible sites. (C) The lowest-energy structure of pre-let-7a3 predicted by Mfold. The red line indicates the 6-mer accessible sites determined from the hybridization experiment. Reprinted with permission from Ref [95]. 
Figure 1

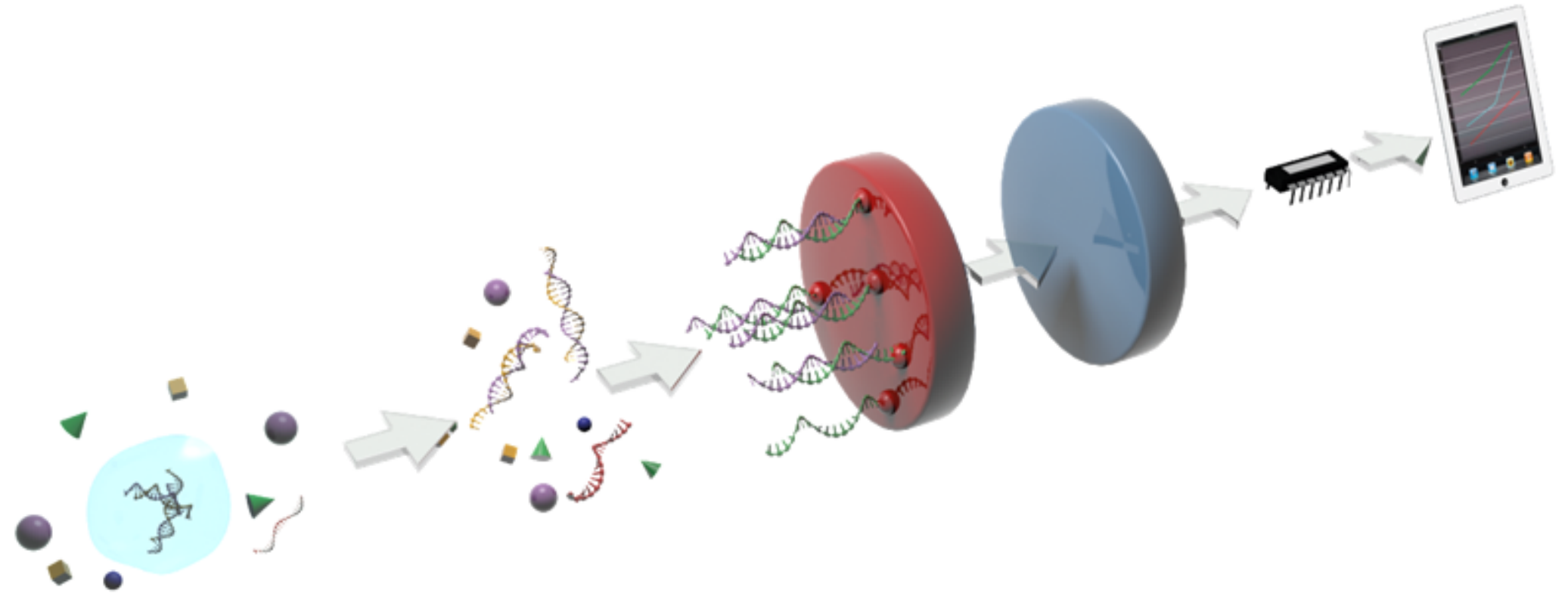


Figure 2

A

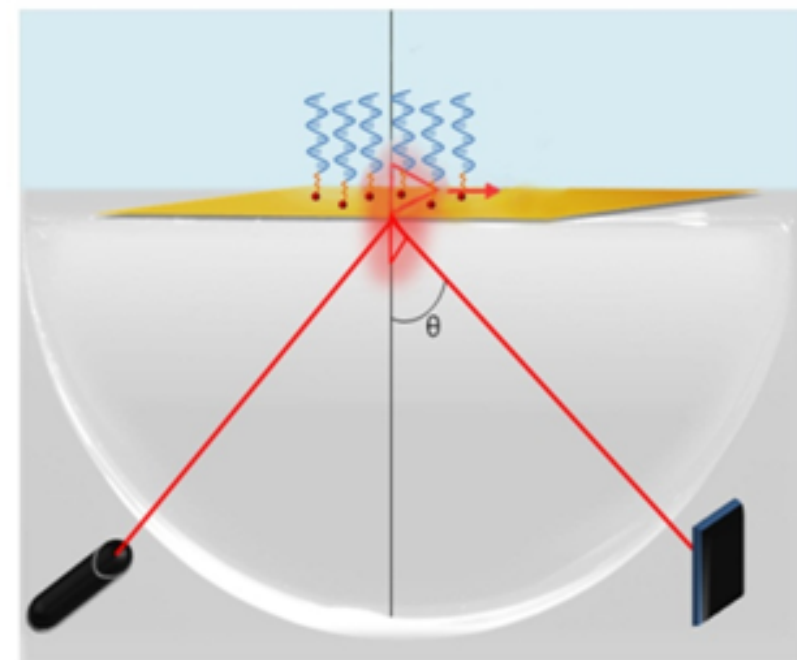

C

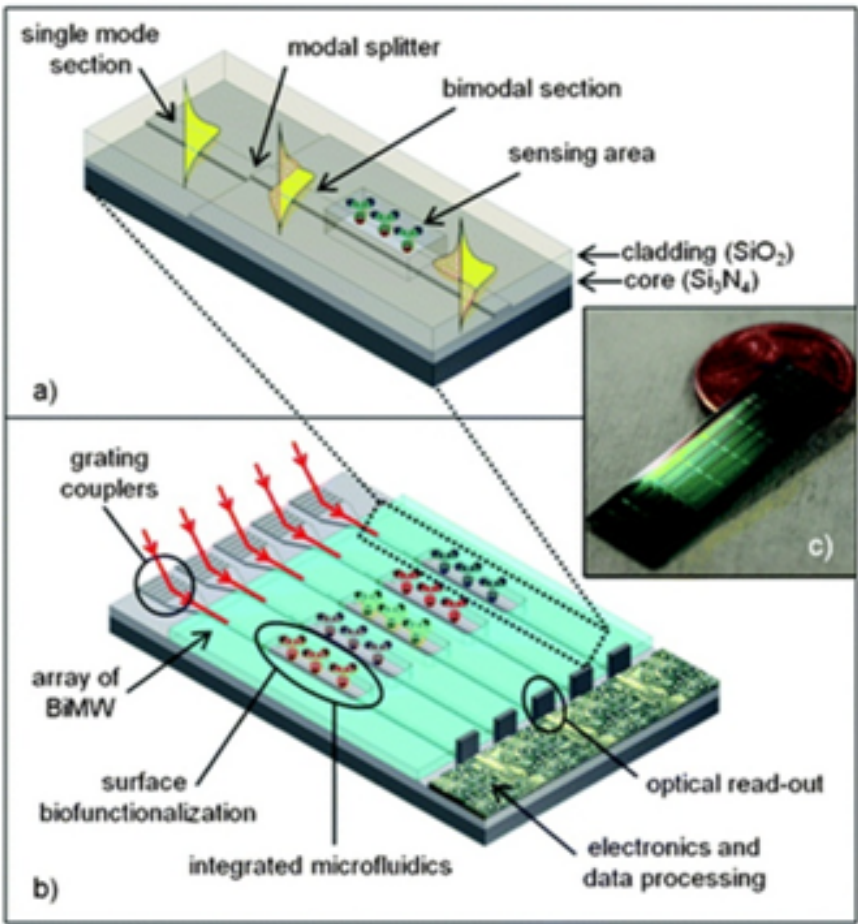

B

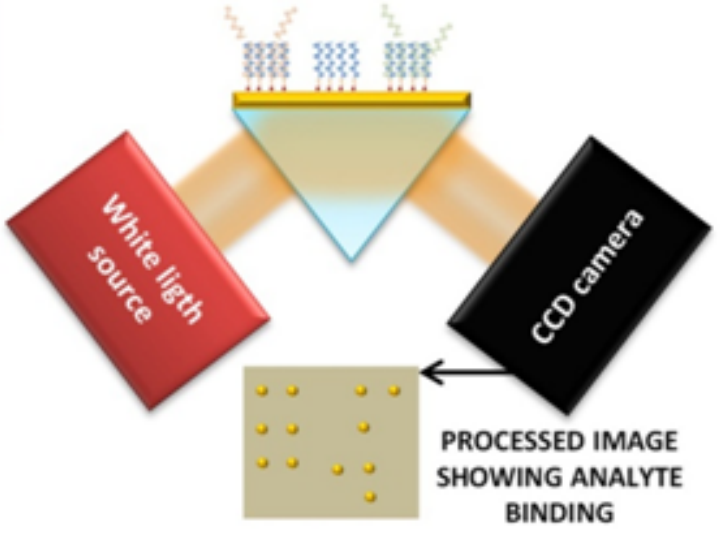

D

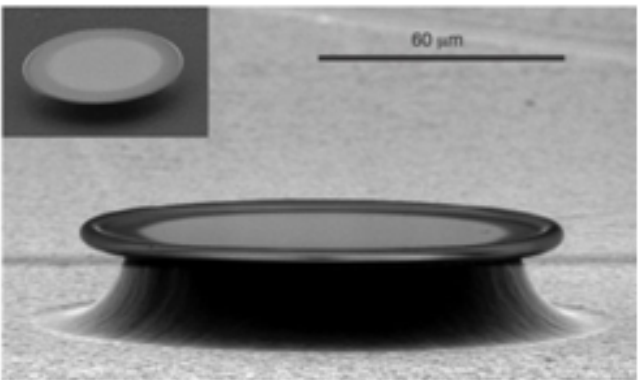

E

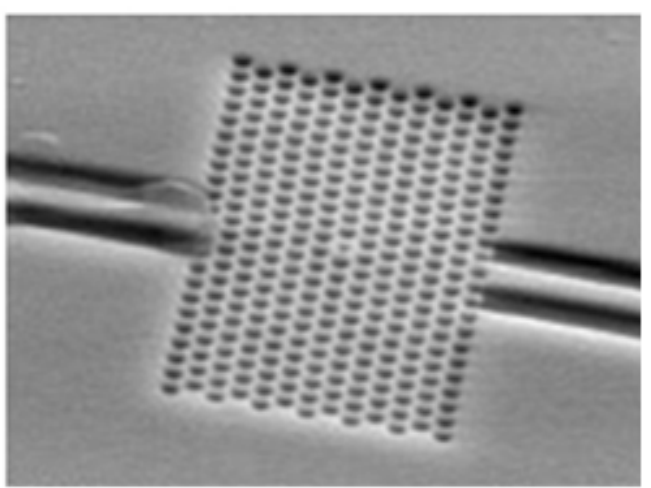




\section{Figure 3}

A
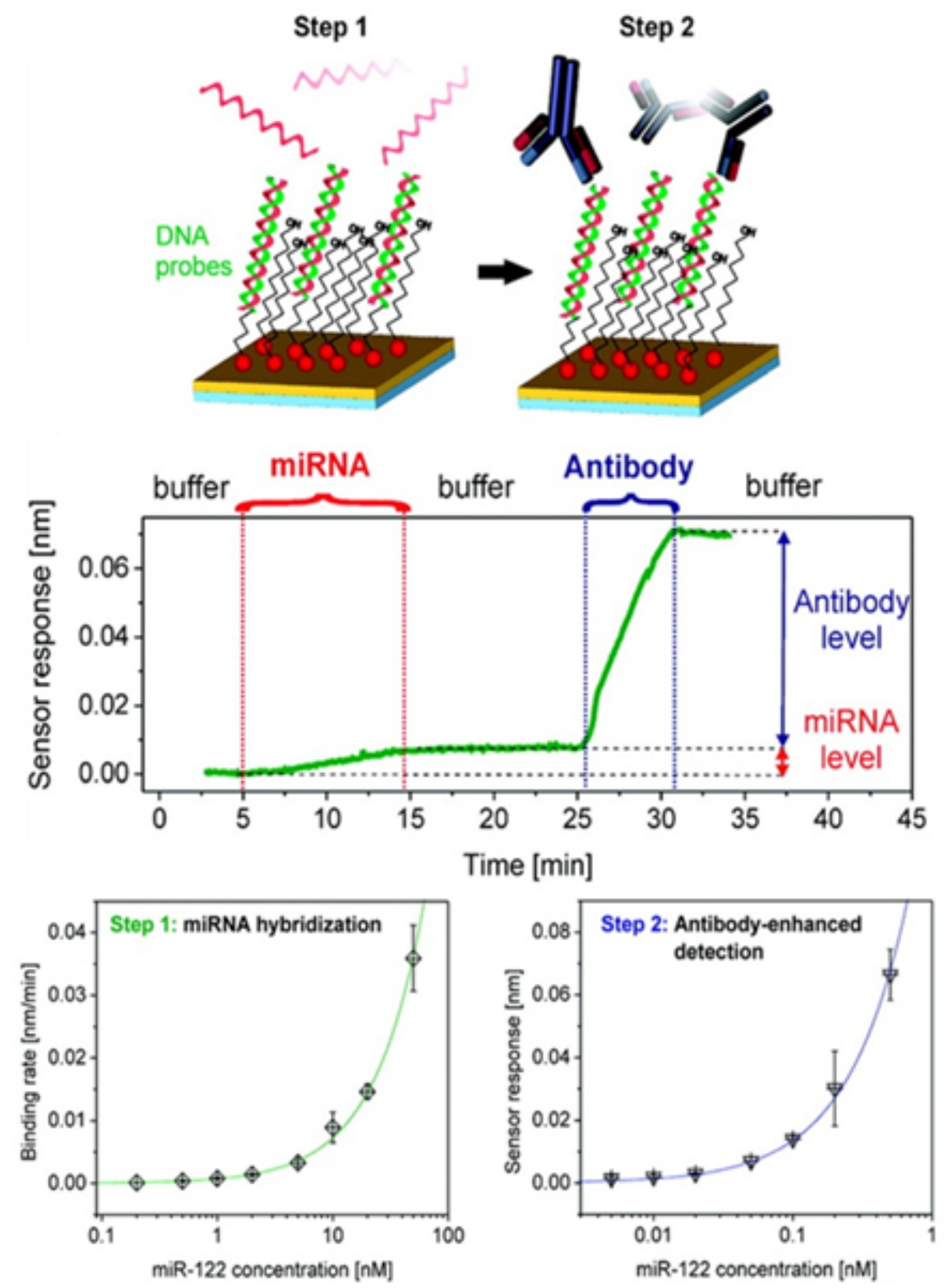

B
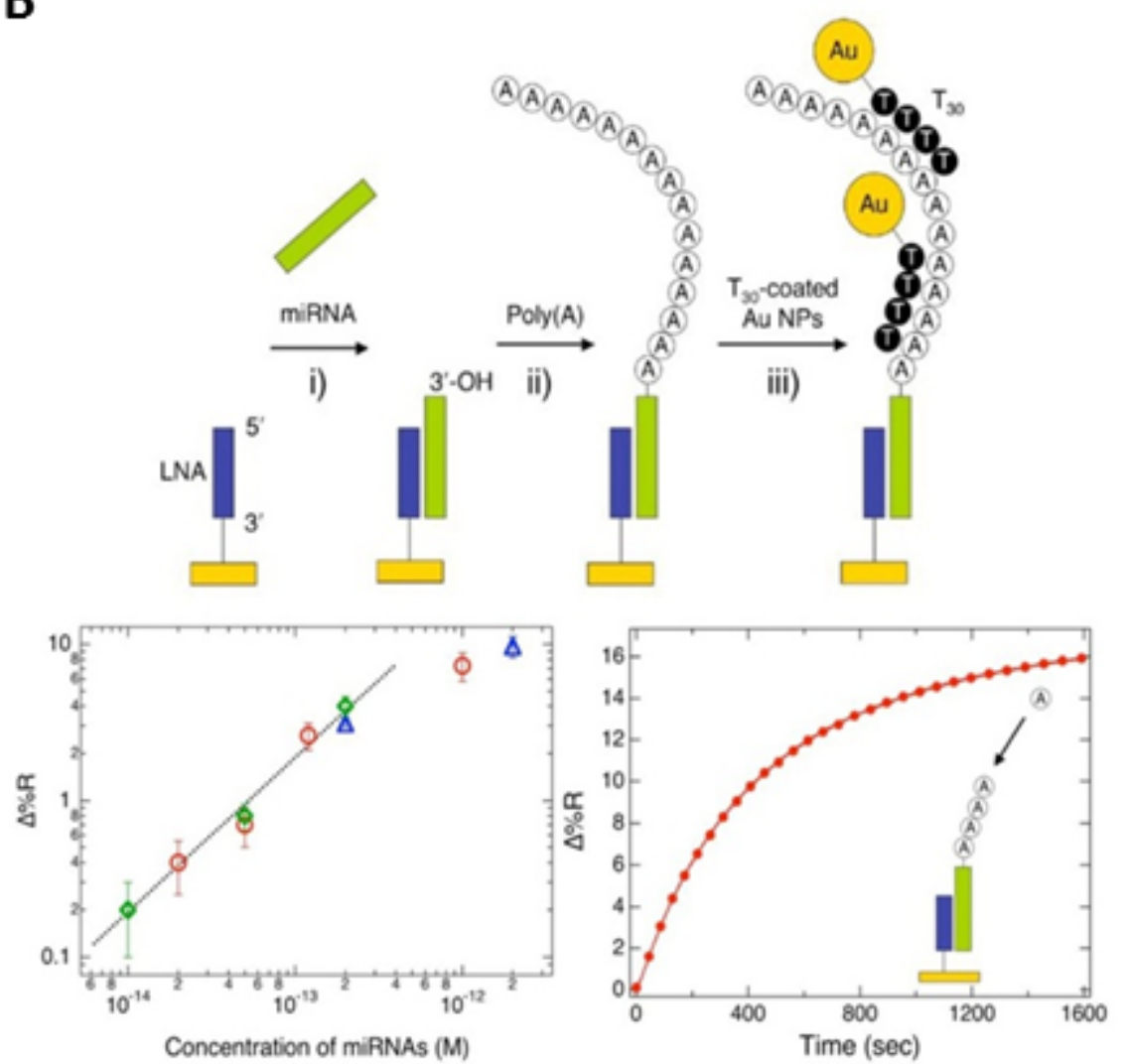

C
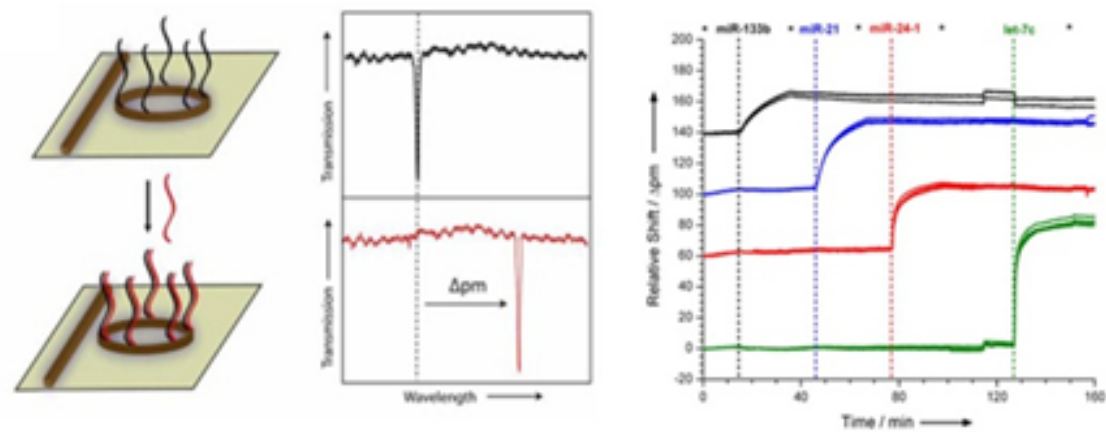


\section{Figure 4}

A

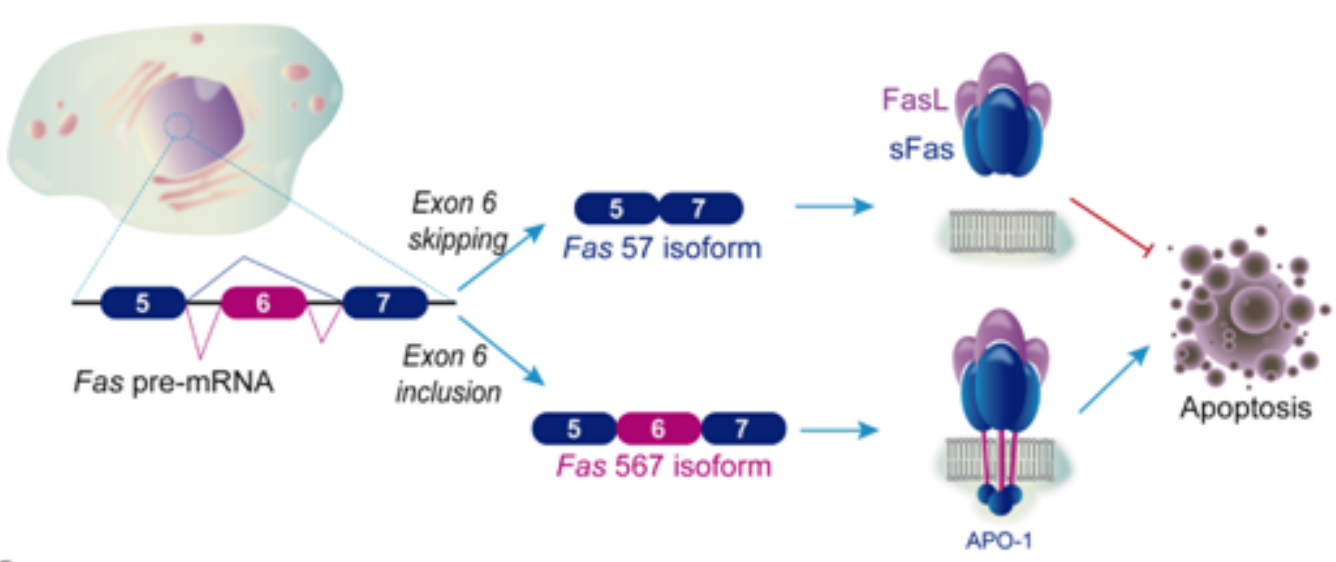

C
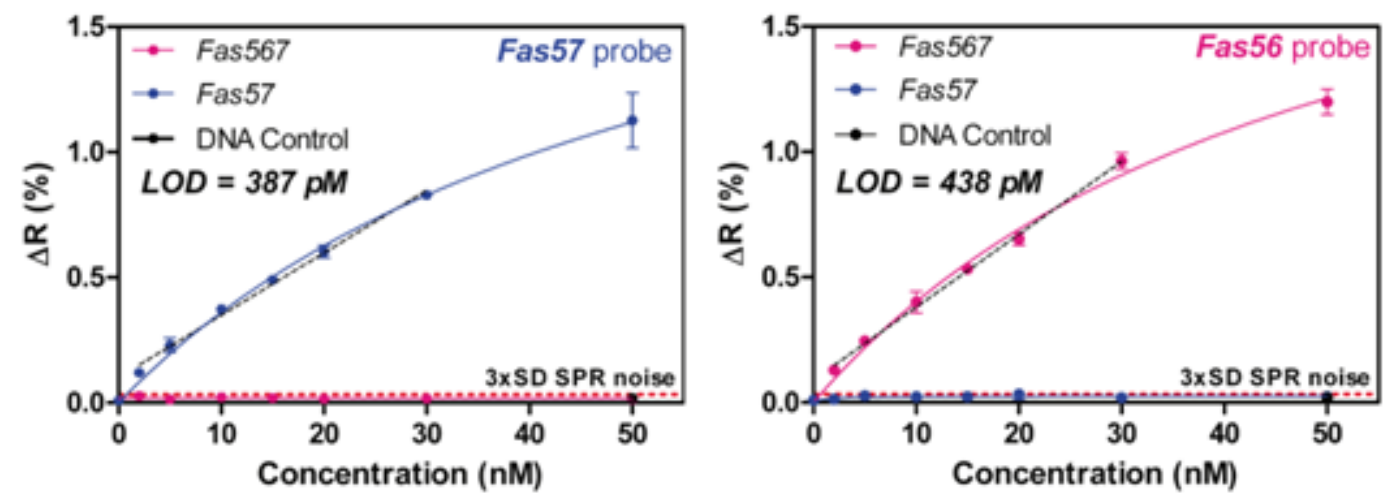

B
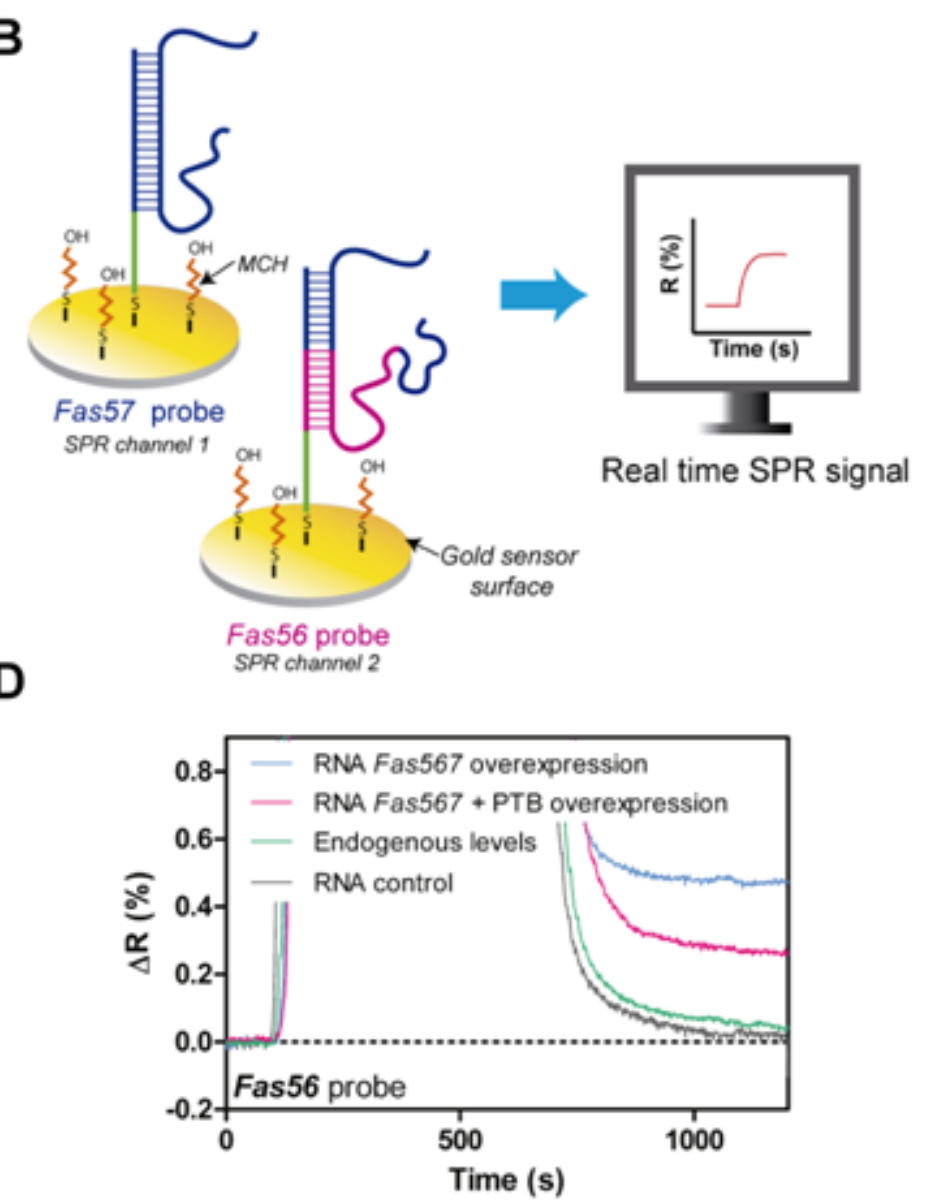


\section{Figure 5}

A

HG-forming strand

WC-forming strand

- 8-amino-adenine

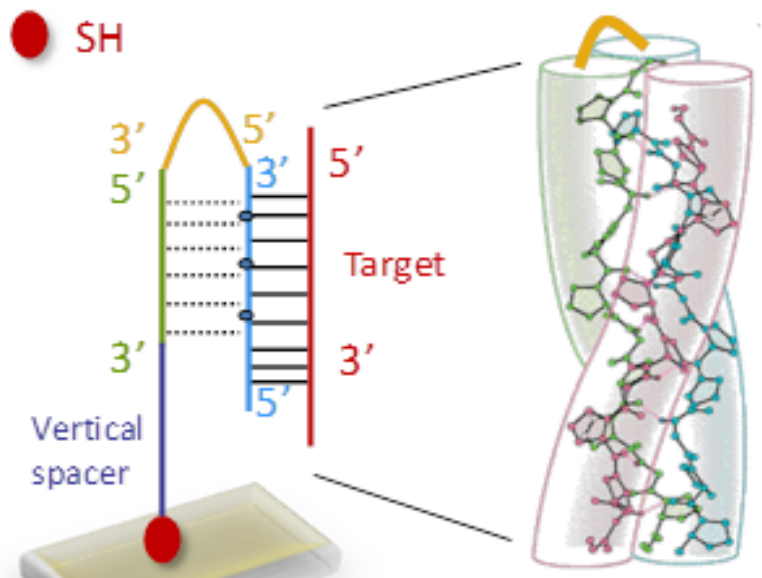

C

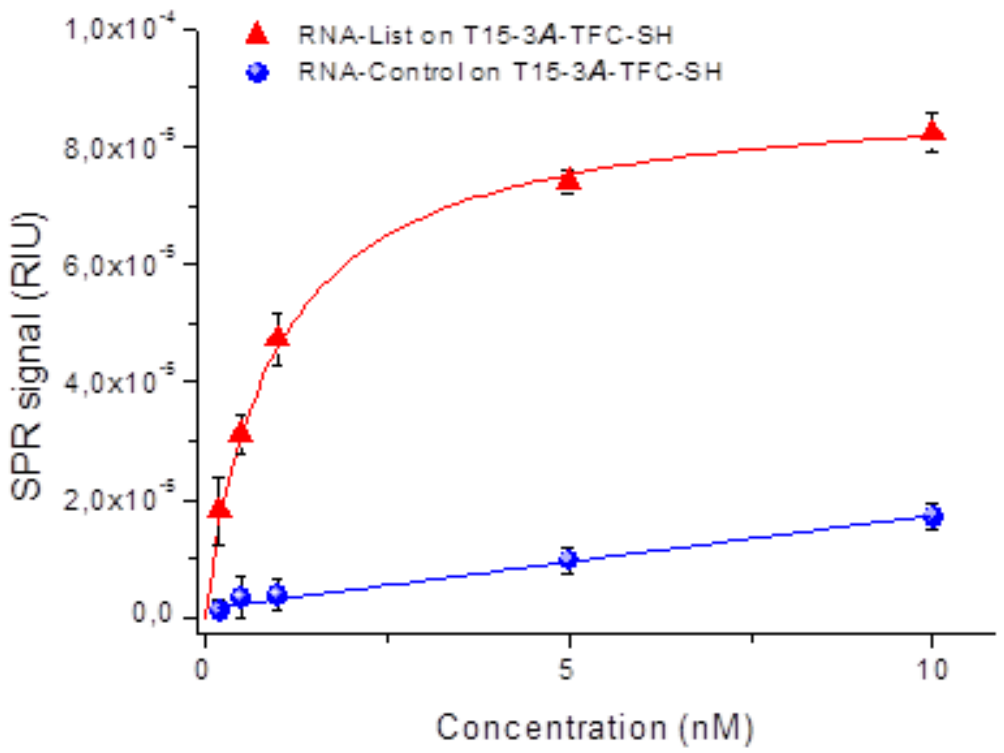

B
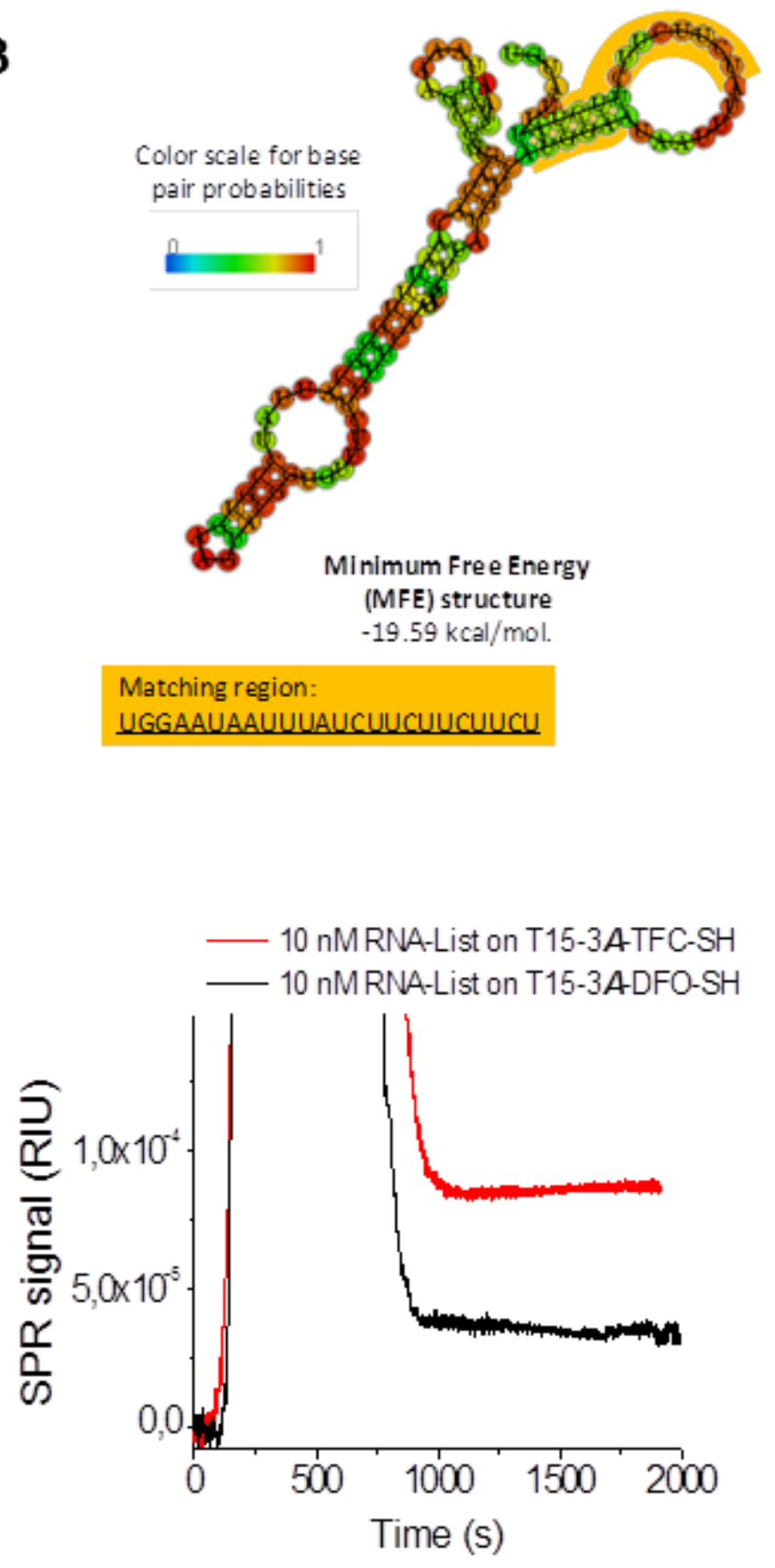
Figure 6

A

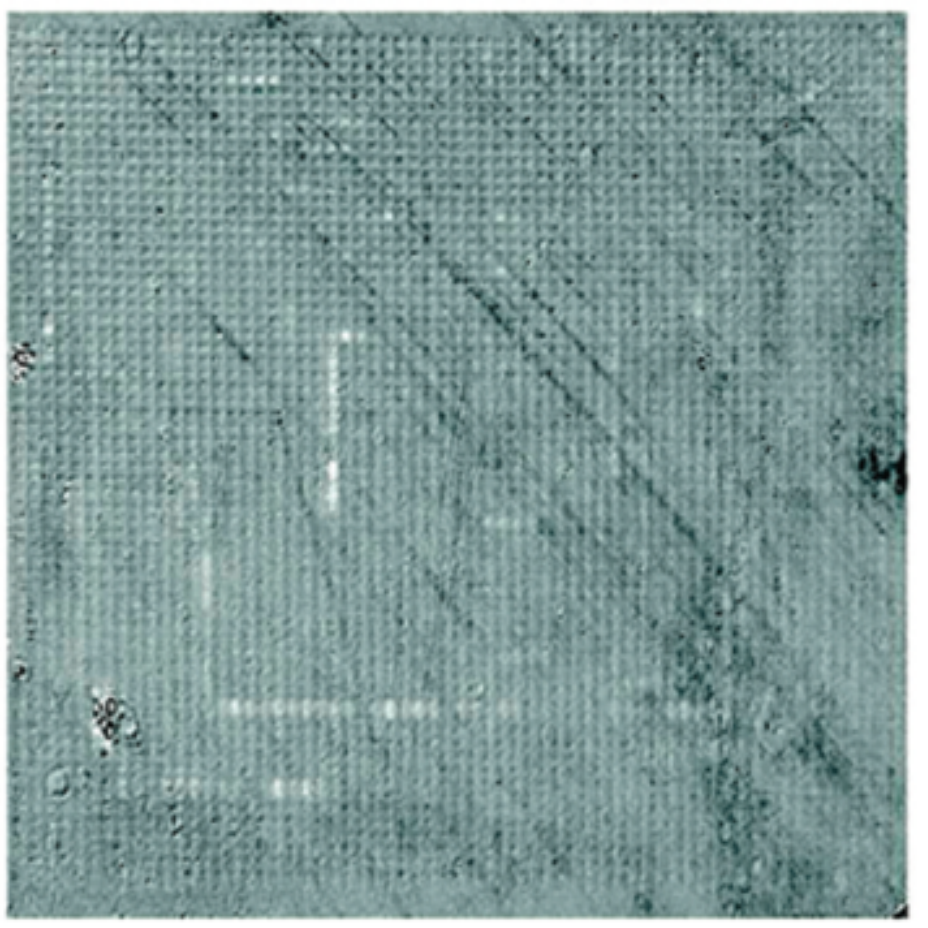

B

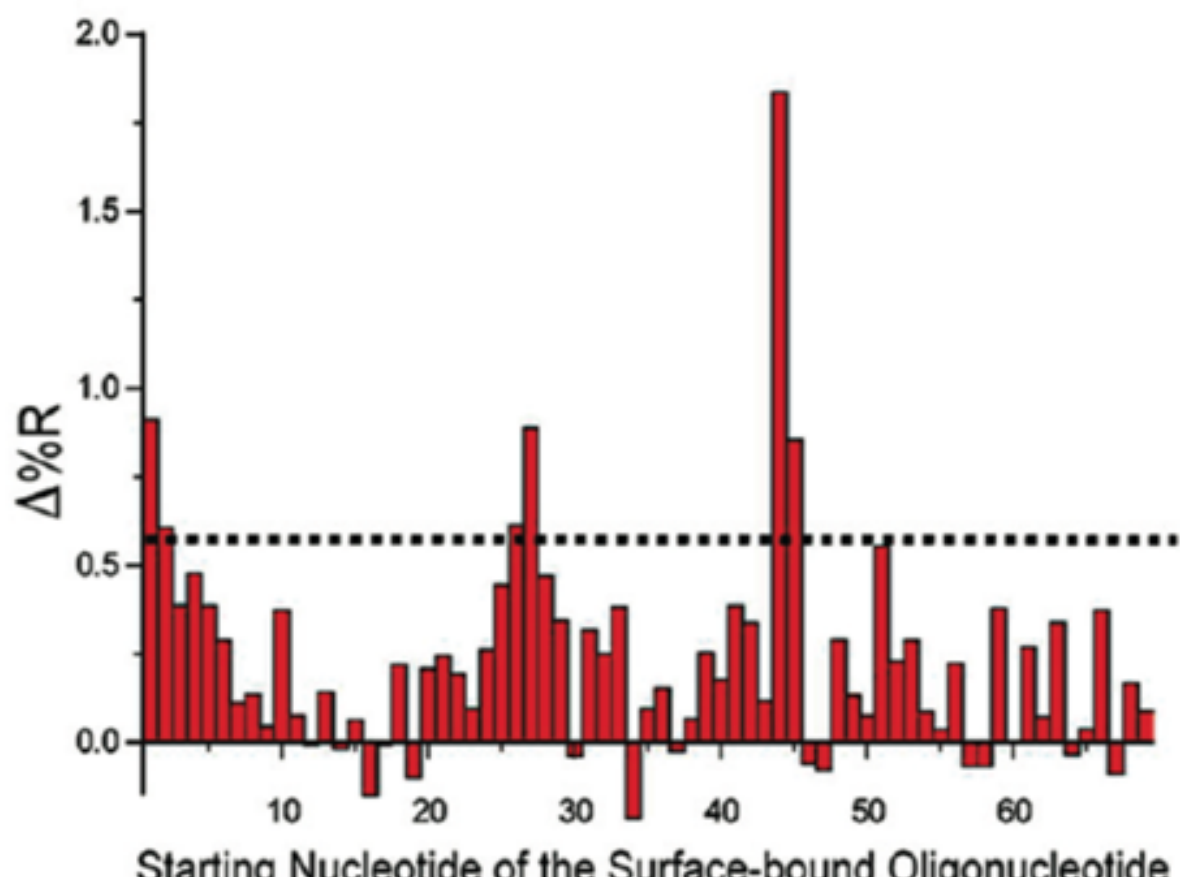

C

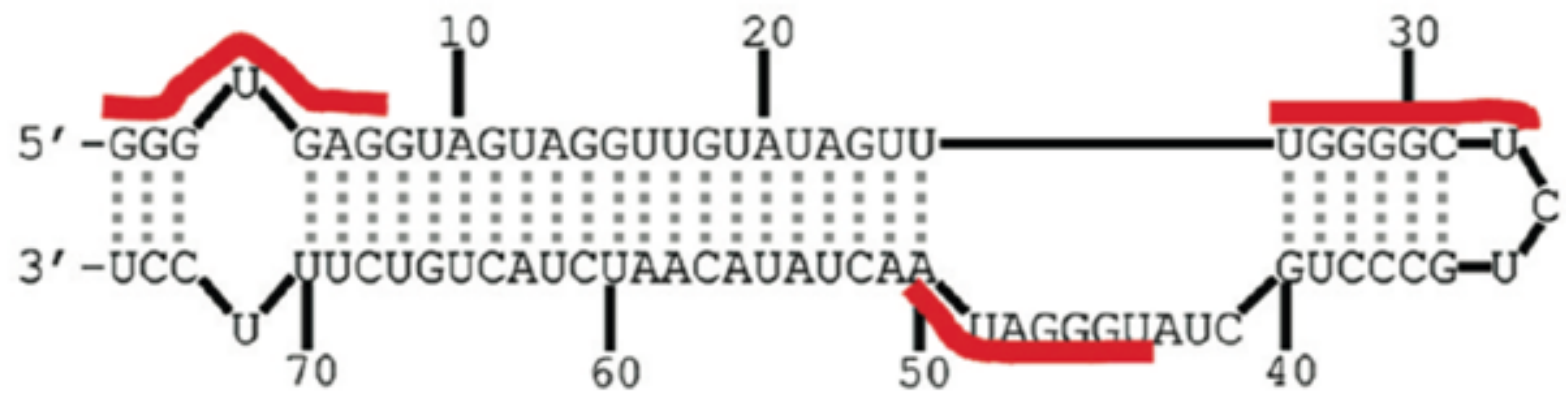




\begin{tabular}{|c|c|c|c|c|c|c|c|}
\hline \multirow{2}{*}{ TYPE } & \multirow{2}{*}{\multicolumn{2}{|c|}{ SUBTYPE }} & \multicolumn{2}{|c|}{ NAME } & \multirow{2}{*}{ SIZE } & \multirow{2}{*}{ FUNCTION } & \multirow{2}{*}{ SITE OF ACTION } \\
\hline & & & Long name & Short name & & & \\
\hline Coding & \multicolumn{2}{|c|}{ Messenger RNA } & messenger RNA & mRNA & & $\begin{array}{l}\text { Encode the information for protein } \\
\text { production; Represent } \sim 2 \% \text { of the } \\
\text { genomic output }\end{array}$ & Cytoplasm \\
\hline \multirow{12}{*}{$\begin{array}{c}\text { Non-coding } \\
\text { (Do not } \\
\text { encode } \\
\text { information } \\
\text { for proteins; } \\
\text { play } \\
\text { structural or } \\
\text { regulatory } \\
\text { roles) }\end{array}$} & \multirow{4}{*}{\multicolumn{2}{|c|}{$\begin{array}{l}\text { House-keeping or } \\
\text { Structural ncRNAs }\end{array}$}} & Ribosomal RNA & rRNAs & $\begin{array}{l}100-5000 \mathrm{nt} \\
\text { depending } \\
\text { on the } \\
\text { subunit }\end{array}$ & \multirow{3}{*}{$\begin{array}{l}\text { Provide the machinery for protein } \\
\text { synthesis from mRNA transcripts }\end{array}$} & \multirow{4}{*}{ Cytoplasm } \\
\hline & & & Transfer RNA & tRNAs & $60-95 \mathrm{nt}$ & & \\
\hline & & & $\begin{array}{l}\text { Small nuclear } \\
\text { RNA (including } \\
\text { spliceosomal }\end{array}$ & sn-RNAs & $80-350 \mathrm{nt}$ & & \\
\hline & & & $\begin{array}{l}\text { Small nucleolar } \\
\text { RNA }\end{array}$ & sno-RNAs & $48-250 \mathrm{nt}$ & $\begin{array}{l}\text { Modify ribosomal RNAs (rRNAs) by } \\
\text { orchestrating the cleavage of the long } \\
\text { pre-rRNA into its functional subunits }\end{array}$ & \\
\hline & \multirow{8}{*}{$\begin{array}{l}\text { Regulatory } \\
\text { ncRNAs }\end{array}$} & \multirow{4}{*}{$\begin{array}{l}\text { Long } \\
\text { ncRNAs }\end{array}$} & \begin{tabular}{|c} 
Long intergenic \\
ncRNAs including \\
very long \\
intergenic ncRNAs \\
\\
\\
Promoter \\
associated ncRNAs
\end{tabular} & $\begin{array}{l}\text { LincRNAs } \\
\text { and } \\
\text { vlincRNAs }\end{array}$ & $\begin{array}{c}200 \mathrm{nt} \text { up to } \\
1 \mathrm{Mb}\end{array}$ & $\begin{array}{l}\text { They regulate protein expression by } \\
\text { diverse mechanisms: } \\
\text { - As guides and tethers for } \\
\text { chromatin-modifying complexes } \\
\text { - As molecular scaffolds for protein } \\
\text { complexes that lack protein-protein } \\
\text { interaction domains } \\
\text { - By binding to transcription factors } \\
\text { to preventing them from binding to } \\
\text { their target DNA sequence } \\
\text { - By interacting directly with other } \\
\text { ncRNAs (e.g. microRNAs) to prevent } \\
\text { them from binding to mRNA. }\end{array}$ & \multirow{4}{*}{$\begin{array}{l}\text { Nucleous or } \\
\text { Cytoplasm }\end{array}$} \\
\hline & & & $\begin{array}{c}\text { Natural Antisense } \\
\text { Transcripts }\end{array}$ & NATs & $\begin{array}{l}200 \mathrm{nt} \text { to } \\
>100 \mathrm{~Kb}\end{array}$ & $\begin{array}{l}\text { DNA replication interference, chromatin } \\
\text { remodeling, transcriptional regulation, } \\
\text { RNA masking, double-stranded RNA } \\
\text { (dsRNA) mediated siRNA mechanism } \\
\text { and translation interference }\end{array}$ & \\
\hline & & & $\begin{array}{l}\text { Transcripts } \\
\text { derived from } \\
\text { repetitive } \\
\text { elements } \\
\text { including } \\
\text { Pseudogenes } \\
\text { derived ncRNAs }\end{array}$ & repRNAs & $\begin{array}{l}200 \mathrm{nt} \text { to } \\
>100 \mathrm{~Kb}\end{array}$ & $\begin{array}{l}\text { influence gene and pseudogene } \\
\text { expression, at both epigenetic and post- } \\
\text { transcriptional levels. }\end{array}$ & \\
\hline & & & \multicolumn{2}{|c|}{$\begin{array}{l}\text { Intronic RNAs including circular } \\
\text { intronic RNAs (ciRNAs) }\end{array}$} & $\begin{array}{l}200 \mathrm{nt} \text { to } \\
\text { several } \mathrm{Kb}\end{array}$ & $\begin{array}{l}\text { Epigenetic regulators of transcription in } \\
\text { cis/in trans }\end{array}$ & \\
\hline & & \multirow{4}{*}{$\begin{array}{c}\text { Small } \\
\text { ncRNAs }\end{array}$} & $\begin{array}{c}\text { Small interfering } \\
\text { ncRNAs }\end{array}$ & si-RNAs & $\sim 20 \mathrm{nt}$ & $\begin{array}{l}\text { Post-transcriptionally regulate mRNA } \\
\text { stability and translation }\end{array}$ & \multirow{4}{*}{$\begin{array}{l}\text { Nucleous or } \\
\text { Cytoplasm }\end{array}$} \\
\hline & & & micro RNAs & mi-RNAs & $21-25 \mathrm{nt}$ & $\begin{array}{l}\text { Post-transcriptionally regulate mRNA } \\
\text { stability and translation. It can also } \\
\text { silence genes transcriptionally. }\end{array}$ & \\
\hline & & & Tiny RNAs & ti-RNAs & $<22 \mathrm{nt}$ & $\begin{array}{l}\text { Regulate initiation of transcription and } \\
\text { gene expression by controlling RNA } \\
\text { polymerase II binding and behaviors, } \\
\text { and modulating local epigenetic } \\
\text { structure associated with transcription } \\
\text { initiation, but not elongation. }\end{array}$ & \\
\hline & & & $\begin{array}{l}\text { Piwi-interacting } \\
\text { ncRNAs }\end{array}$ & pi-RNAs & $20-30 \mathrm{nt}$ & $\begin{array}{l}\text { Guide modification of chromatin } \\
\text { structure in the nucleus, thereby } \\
\text { contributing to the establishment and } \\
\text { maintenance of distinct chromatin } \\
\text { domains. }\end{array}$ & \\
\hline
\end{tabular}


Table 2

\begin{tabular}{|c|c|c|c|c|c|}
\hline RNA type & Sample source & Method & Sensitivity & Single/Multiplex detection & Reference \\
\hline \multirow{11}{*}{ miRNA } & $\begin{array}{c}\text { Mouse liver total } \\
\text { RNA }\end{array}$ & SPR & $0.2 \mathrm{nM}-2 \mathrm{pM}$ & Single & Sipova et al. [77] \\
\hline & Synthetic RNA & SPRi & $40 \mathrm{nM}-4 \mathrm{nM}$ & Single & Nasheri et al. [78] \\
\hline & Synthetic RNA & SPRi & $10 \mathrm{fM}$ & Multiplex & Fang et al. [56] \\
\hline & $\begin{array}{c}\text { Mouse liver total } \\
\text { RNA } \\
\end{array}$ & SPRi & fMlevel & Multiplex & Fang et al. [56] \\
\hline & Synthetic RNA & $\begin{array}{c}\text { Nanoparticle- } \\
\text { Enhanced } \\
\text { Diffraction } \\
\text { Gratings } \\
\text { (NEDG) } \\
\end{array}$ & $50 \mathrm{pM}$ & Single & Lee et al. [80] \\
\hline & Synthetic RNA & SPRi & $100 \mathrm{fM}$ & Multiplex & Zhou et al. [81] \\
\hline & Total plasma RNA & LSPR & $23-35 \mathrm{fM}$ & Multiplex & Joshi et al. [82] \\
\hline & $\begin{array}{c}\text { Human plasma } \\
\text { samples without } \\
\text { RNAs extraction }\end{array}$ & LSPR & fMlevel & Multiplex & Joshi et al. [82] \\
\hline & $\begin{array}{c}\text { Cell-line } \\
\text { extracted total } \\
\text { RNA }\end{array}$ & $\begin{array}{l}\text { Arrays of } \\
\text { silicon } \\
\text { microring } \\
\text { resonators }\end{array}$ & $2 \mathrm{nM}$ & Multiplex & Qavi et al. [83] \\
\hline & Synthetic RNA & SERS & $\mu \mathrm{M}$ & Multiplex & Driskell et al. [84] \\
\hline & Urine samples & $\mathrm{MZI}$ & $1 \mathrm{fM}$ & Multiplex & Liu et al. [85] \\
\hline \multirow[t]{2}{*}{ mRNA } & \multirow[t]{2}{*}{$\begin{array}{c}\text { Cell-line } \\
\text { extracted total } \\
\text { RNA }\end{array}$} & $\begin{array}{l}\text { Arrays of } \\
\text { silicon } \\
\text { microring } \\
\text { resonators }\end{array}$ & $160 \mathrm{pM}$ & Multiplex & Kindt et al. [87] \\
\hline & & SPR & pM level & Multiplex & Huertas et. al [88] \\
\hline $\begin{array}{c}\text { viral ssRNA } \\
25-79 \mathrm{nt}\end{array}$ & Synthetic RNA & $\begin{array}{c}\text { Scattering on } \\
\text { gold } \\
\text { nanoparticles }\end{array}$ & $80 \mathrm{pM}$ & Single & Griffin et al. [89] \\
\hline $\begin{array}{l}\text { triplex- } \\
\text { forming } \\
\text { RNAs }\end{array}$ & $\begin{array}{c}\text { In-vitro } \\
\text { transcribed RNA } \\
\text { (96nt) } \\
\end{array}$ & SPR & $200 \mathrm{pM}$ & Single & Carrascosa et al. [92] \\
\hline \multirow{2}{*}{ rRNA } & \multirow{2}{*}{$\begin{array}{c}\text { E. Coli extracted } \\
\text { total RNA }\end{array}$} & SPR & $10 \mathrm{fM}$ & Single & Joung et al. [97] \\
\hline & & SPRi & $3.8 \mathrm{nM}$ & Multiplex & Nelson et al. [98] \\
\hline
\end{tabular}

